\title{
A Novel Approach in Analyzing Aromaticity by Homo- and Isostructural Reactions: An ab Initio Study of Fluorobenzenes
}

\author{
Danijela Barić, ${ }^{\dagger}$ Borislav Kovačević, $\dagger$ Zvonimir B. Maksić, $, \dagger, \dagger$ and Thomas Muiller ${ }^{\S}$ \\ Quantum Organic Chemistry Group, Rudjer Bošković Institute, POB 180, 10002 Zagreb, Croatia, Division of \\ Physical Chemistry, Faculty of Science and Mathematics, The University of Zagreb, Marulicev trg 19, 10000 \\ Zagreb, Croatia, and Central Institute of Applied Mathematics, Research Center Jülich, 52425 Jülich, Germany
}

Received: June 18, 2005; In Final Form: September 23, 2005

\begin{abstract}
The influence of fluorine substitutions on the stability of benzene is examined by using the Hartree-Fock (HF) and MP2 models. It is conclusively demonstrated that homodesmotic reactions based on the open-chain zigzag polyenes are unsatisfactory. A comparison of the intramolecular interactions of educts and products shows that they are not well balanced. Hence, these reactions should be abandoned in discussing aromaticity. A much better vehicle for exploring aromaticity is provided by homostructural reactions, which employ cyclic monoene and diene as reference model compounds. Their heavy atoms are enforced to assume planar geometries to enable $\sigma / \pi$ separation. The HF/cc-pVTZ calculations show that extrinsic aromaticity of benzene $\mathbf{B} \Delta E(\text { ease })_{\mathbf{B}}$ arises both from the $\sigma$ - and $\pi$-contributions. They are -14.8 and $-23.1 \mathrm{in} \mathrm{kcal} / \mathrm{mol}$, respectively, if the stockholder energy partitioning scheme is employed. This result implies that both the $\sigma$ - and $\pi$-frameworks contribute to the aromatic stabilization of $\mathbf{B}$, the latter being more important. The total aromatic stabilization $\Delta E$ (ease $)_{\mathbf{B}}$ is $-37.9 \mathrm{kcal} / \mathrm{mol}$. Schleyer's indene-isoindene isomerization approach also strongly indicates that the decisive factor in determining the aromatic stability of the benzene moiety is the $\pi$-electron framework. The origin of extrinsic aromaticity is identified as the increased nuclear-electron attraction of both $\sigma$ - and $\pi$-electrons, if 1,3-cyclohexadiene is used as a gauge compound. Further, by using a system of isostructural reactions, it is conclusively demonstrated that fluorobenzenes exhibit a remarkable additivity of the substituent effects, as far as the stability of multiply substituted benzenes is concerned. This additivity rule is so accurate that it enables delineation of the fluorine repulsions and the aromaticity defect $\Delta E(\mathrm{AD})$. It appears that the $\Delta E(\mathrm{AD})$ values increase upon sequential fluorine substitution at the next nearest (vicinal) position thus making multiply fluorinated benzenes less stable.
\end{abstract}

\section{Introduction}

The empirical notion of aromaticity is one of the cornerstones of organic chemistry, inorganic chemistry, and biochemistry. In view of its tremendous practical importance, it is very unfortunate that aromaticity cannot be rigorously defined. Namely, aromaticity is not an observable (a measurable quantity) and there is no quantum mechanical operator which would enable its exact definition and determination. Hence, aromaticity remains hidden and elusive-just like its counterpart antiaromaticity, or hybridization and electronegativity-despite its indirect and numerous experimental manifestations, be they structural, magnetic, or energetic features. It follows that the extent of aromatic stabilization of various compounds can be estimated only by selecting some nonaromatic reference systems, which are more or less arbitrary. Dewar and co-workers ${ }^{1,2}$ argued that acyclic polyenes were ideal gauge molecules, since they were free of cyclic conjugation and exhibited additivity in their enthalpies of formation. In other words, open chain polyenes behave as if they were perfectly localized $\pi$-systems. This viewpoint was predominantly adopted by a majority of researchers for decades, using various arguments originating

* Corresponding author. Fax: +385-1-4561-118. E-mail: zmaksic@ spider.irb.hr.

†udjer Bošković Institute.

$\doteqdot$ University of Zagreb.

$\S$ Central Institute of Applied Mathematics. from the early $\pi$-electron theories of the electronic structure of planar molecules, to the most recent all-electron ab initio methods. A particularly useful concept in this respect was put forward by George and co-workers, ${ }^{3-6}$ by the so-called "gedanken" homodesmotic reactions, which have faithfully served chemistry until nowadays. Within this conceptual framework the aromaticity of closed $\pi$-electron rings was defined by using the linear zigzag polyenes as gauge systems. An alternative approach was offered by Kistiakowsky et al., ${ }^{7,8}$ based on successive hydrogenation of the paradigmatic benzene, leading to 1,3-cyclohexadiene and cyclohexene as the end products and consequently as the nonaromatic reference compounds. Historically speaking, the first researcher who found unusual stability of benzene in the hydrogenation experiments, and who should get credit for this finding, was Stohmann. ${ }^{9,10}$

The list of molecular properties affected by aromaticity is rather long, leading to different scales of this elusive feature and to some controversies corresponding to different personal preferences. ${ }^{11-14} \mathrm{~A}$ general consensus seems to be that there is no generally acceptable definition of aromaticity, which would put all aromatic compounds on the same ladder, particularly if various molecular properties were considered. ${ }^{14,15}$ This is not surprising since different molecular properties probe different portions of the electron distribution in molecules. Two most important criteria of aromaticity are given by the magnetic ${ }^{16-24}$ 
and thermodynamic properties. ${ }^{3-6}$ Structural features should be mentioned too. ${ }^{25,26}$

The physical origin of aromaticity is also a matter of dispute even in the archetypal benzene. The fact that aromaticity is always connected to conjugated cyclic $\pi$-systems, coupled with the fact that $\pi$-electrons are weakly bound and highly mobile, has led to a widely accepted traditional opinion that aromatic stabilization is a consequence of the $\pi$-electron network. The Hückel molecular orbital (HMO) formalism in its simplest original form ${ }^{27,28}$ provided theoretical support to this intuitive notion. ${ }^{29,30}$ However, there were alternative views starting as early as 1959 by Longuet-Higgins and Salem and others, ${ }^{31-36}$ which have culminated by a series of papers of Shaik, Hiberty, Jug and others, ${ }^{37-39}$ indicating that aromaticity and $D_{6 h}$ symmetry of benzene arose due to its $\sigma$-electron framework. Recently, we have shown, by using the concept of homodesmotic reactions, ${ }^{3-6}$ that if the linear zigzag polyenes were taken as traditional reference nonaromatic systems, then several interesting conclusions would straightforwardly follow. ${ }^{40}$ First, the aromaticity of benzene can be estimated at the HartreeFock (HF) level, since the electron correlation and zero point vibrational energy effect cancel to a large extent. Within this context it was shown that Dunning's correlation consistent basis set of the cc-pVTZ ${ }^{41}$ quality yielded results close to infinite basis (IB) set. Further, the aromatic stabilization of benzene does not depend on the particular selection of the open chain zigzag polyene as a reference system. In other words, aromaticity is invariant to the choice of the homodesmotic reactions in a semiquantitative sense, provided their specific subclass based on the zigzag polyenes is used as a gauge. Finally, it was pointed out that it was impossible to separate the $\sigma$-and $\pi$-interactions either a priori or a posteriori (i.e. after the all-electron ab initio calculations) in an unambiguous way, because the $\sigma$ - and $\pi$-electrons are coupled by the $V_{\mathrm{ee}}^{\sigma \pi}$ and $V_{\mathrm{nn}}$ repulsion terms. The latter is particularly difficult to resolve into the $\sigma$ - and $\pi$-components, since it only implicitly depends on the $\sigma$-and $\pi$-electron densities via Born-Oppenheimer (BO) potential energy (hyper)surfaces (PES). However, a simple stockholder criterion was offered as a possible solution, since it was capable of taking into account a large difference in the number of the $\sigma$ - and $\pi$-electrons in aromatic systems. A careful analysis performed within the described framework has shown that the aromatic stabilization of benzene was a result of the more favorable $\sigma$-type interactions. The energetic terms leading to the aromatic stabilization were more favorable repulsions between the electrons and between the nuclei compared to open chain zigzag polyenes.

Building on these results and continuing our ongoing investigations of aromaticity and antiaromaticity, we felt it worthwhile to extend analysis to alternative homodesmotic reactions and to substituted benzenes, in order to elucidate the influence of a large variety of substituents on the stability of this aromatic system par excellence. The first explored substituent is fluorine, since it is highly electronegative and has a distinct advantage that its steric demands are very modest due to its small size. Our analysis of fluorinated benzenes is based on several types of homodesmotic and isomerization reactions focusing on the energetic properties. The present report describes some unexpected findings obtained during this study, which seem to have far reaching consequences.

\section{Theoretical Framework}

The theoretical model used is the HF approach employing Dunning's cc-pVDZ and cc-pVTZ basis sets. According to our earlier results, ${ }^{40}$ this model should provide a reasonable description of aromaticity in benzene systems. However, a brief comment on the influence of the electron correlation estimated at the MP2 level and the zero point vibrational energies (ZPVE) calculated by the HF model will be made. As a final remark, it should be mentioned that the HF energies are scaled in order to satisfy virial theorem, if not stated otherwise. All calculations have been carried out by using GAUSSIAN 03 code. ${ }^{42}$

\section{Results and Discussion}

3.1. Homodesmotic Reactions with Linear Polyenes. The fluorinated benzenes $\mathbf{1 - 6}$ studied here are depicted in Figure 1 together with ethylene $\mathbf{7}$ and 1,3-butadiene 11, as well as their fluoroderivatives to be used in homodesmotic reactions 1-7 defined below. The parent compound benzene, serving as a reference, is denoted by $\mathbf{B}$. The system of homodesmotic reactions based on the zigzag polyenes reads

$$
\begin{gathered}
\mathbf{B}+3(\mathbf{7})=3(\mathbf{1 1})+E(\text { ease })_{\mathbf{B}} \\
\mathbf{1}+3(\mathbf{7})=2(\mathbf{1 1})+\mathbf{1 2}+\Delta E(\mathbf{1}) \\
\mathbf{2}+2(\mathbf{7})+(\mathbf{9})=\mathbf{1 1}+2(\mathbf{1 4})+\Delta E(\mathbf{2}) \\
\mathbf{3}+\mathbf{7}+\mathbf{8}+\mathbf{9}=\mathbf{1 3}+\mathbf{1 4}+\mathbf{1 5}+\Delta E(\mathbf{3}) \\
\mathbf{4}+\mathbf{7}+2(\mathbf{9})=2(\mathbf{1 4})+\mathbf{1 7}+\Delta E(\mathbf{4}) \\
\mathbf{5}+\mathbf{8}+2(\mathbf{9})=\mathbf{1 5}+\mathbf{1 6}+\mathbf{1 7}+\Delta E(\mathbf{5}) \\
\mathbf{6}+3(\mathbf{1 0})=3(\mathbf{1 8})+\Delta E(\mathbf{6})
\end{gathered}
$$

Here $E$ (ease) $)_{\mathbf{B}}$ denotes the extrinsic aromaticity of benzene, which implies that the $\pi$-electron topology is changed in the course of reaction. ${ }^{43}$ It is important to keep in mind that the energetic stabilization is defined as negative quantity. An increase in stability means a decrease in $\Delta E$ value, i.e., more negative $\Delta E$ value and vice versa. The changes in the HF energies $\Delta E(\mathbf{n})$, in homodesmotic reactions $2-7$, where $\mathbf{n}=$ 1-6, cannot be ascribed to the aromatic stabilization of the fluorine substituted benzenes alone. Namely, they also involve through-space interactions of the vicinal $\mathrm{F}$ atoms as e.g. in 2 and some other interactions. An exception is given by the monofluoro derivative $\mathbf{1}$, where a difference $\Delta E(\mathbf{1})-E(\text { ease })_{\mathbf{B}}$ does give a change in the aromatic stabilization upon substitution. The changes in the total HF energies will be discussed in terms of the energy component analysis, which requires the $\sigma / \pi$ separation. The latter is expounded here in some more detail, since it is essential for the understanding of the forthcoming results. It should be noted that the use of cis-1,3-butadiene instead of its trans isomer would introduce a bias in the $\sigma / \pi$ partitioning in fluorinated derivatives due to considerable mixing of the $\sigma$ and $\pi$ AOs. On the other hand, enforced planar cis1,3-butadiene configuration would include undesirable repulsion, which is not present on the left side of eq 1 . We shall come to this point again later on. The total HF energy is given by

$$
E_{\mathrm{HF}}=E(T)_{\mathrm{HF}}+V_{\mathrm{HF}}
$$

where $E(T)_{\mathrm{HF}}$ denotes kinetic energy, whereas $V_{\mathrm{HF}}$ is

$$
V_{\mathrm{HF}}=V_{\mathrm{ne}}+V_{\mathrm{ee}}+V_{\mathrm{nn}}
$$

Here $V_{\text {ne }}, V_{\text {ee }}$, and $V_{\text {nn }}$ stand for the nuclear-electron attraction, electron-electron repulsion, and nuclear-nuclear repulsion, respectively. The first terms in eqs 8 and $9, E(T)_{\mathrm{HF}}$ and $V_{\text {ne, }}$, 
<smiles>Fc1ccccc1</smiles>

1<smiles>Fc1cc(F)c(F)c(F)c1F</smiles>

5<smiles>Fc1ccccc1F</smiles>

2<smiles>Fc1c(F)c(F)c(F)c(F)c1F</smiles>

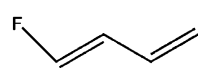

13<smiles>F/C=C(F)/C(F)=C/F</smiles>

17<smiles>Fc1ccc(F)c(F)c1F</smiles>

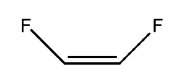

9

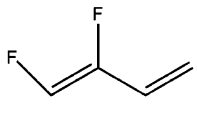

14

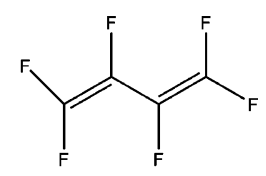

18

Figure 1. Schematic representation of fluorinated benzenes and fluorinated polyenes entering homodesmotic reactions.

respectively, are easily resolved into the $\sigma$ - and $\pi$-contributions in view of the one-electron character of operators $T$ and $1 / r_{\text {ne }}$. However, $V_{\text {ee }}$ and $V_{\mathrm{nn}}$ involve pairwise interactions which cannot be uniquely decomposed into $\sigma$ - and $\pi$-parts. The electron repulsion energy $V_{\mathrm{ee}}=V_{\mathrm{ee}}^{\sigma \sigma}+V_{\mathrm{ee}}^{\sigma \pi}+V_{\mathrm{ee}}^{\pi \pi}$ involves the $V_{\mathrm{ee}}^{\sigma \pi}$ term, which couples the $\sigma$ - and $\pi$-electrons through mutual Coulomb interaction. In our previous work $^{40}$ we suggested a stockholder (SHR) partitioning of the mixed term as an appropriate procedure to disentangle $\sigma$ - and $\pi$-interactions. Specifically, $V_{\mathrm{ee}}=V_{\mathrm{ee}}^{\sigma}+V_{\mathrm{ee}}^{\pi}$, where

$V_{\mathrm{ee}}^{\sigma}=V_{\mathrm{ee}}^{\sigma \sigma}+\left(n_{\sigma} / N\right) V_{\mathrm{ee}}^{\sigma \pi} \quad$ and $\quad V_{\mathrm{ee}}^{\pi}=V_{\mathrm{ee}}^{\pi \pi}+\left(n_{\pi} / N\right) V_{\mathrm{ee}}^{\sigma \pi}$

Here $n_{\sigma}$ and $n_{\pi}$ signify the number of $\sigma$ - and $\pi$-electrons, respectively, whereas $N=n_{\sigma}+n_{\pi}$. Although the stockholder partitioning is simple and appealing, it is by no means sacrosanct or the only possible one. The mixed $V_{\text {ee }}^{\sigma \pi}$ term can be divided for instance 50:50 yielding $V_{\mathrm{ee}}^{\sigma}=V_{\mathrm{ee}}^{\sigma \sigma}+(1 / 2) V_{\mathrm{ee}}^{\sigma \pi}$ and $V_{\mathrm{ee}}^{\pi}=$ $V_{\mathrm{ee}}^{\pi \pi}+(1 / 2) V_{\mathrm{ee}}^{\sigma \pi}$ thus giving rise to the equipartition scheme (EQP). Although the latter does not account for the large disparity in the number of $\sigma$ - and $\pi$-electrons, it offers the advantage that the analysis solely requires the $\mathrm{HF}$ orbital energies, which can be distinguished by the $\sigma$-and $\pi$-symmetry.

Turning to the nuclear repulsion energy $V_{\mathrm{nn}}$, it is important to realize that the decompositions of $V_{\text {ee }}$ and $V_{\mathrm{nn}}$ should be consistent. There should be one-to-one correspondence between electrons and positive charges (protons) in the nuclei. Hence, the total nuclear charges are split into partial positive charges attributed to the $\sigma$ - and $\pi$-framework in such a way that they equal in magnitude the number of the $\sigma$ - and $\pi$-electrons, respectively, belonging to the neutral atom in question. Specifically, for the planar compounds depicted in Figure 1 we have $Z(\mathrm{C})^{\sigma}=5, Z(\mathrm{C})^{\pi}=1, Z(\mathrm{~F})^{\sigma}=7, Z(\mathrm{~F})^{\pi}=2, Z(\mathrm{H})^{\sigma}=1, Z(\mathrm{H})^{\pi}$
$=0$. The intranuclear repulsion between partial $\sigma$ - and $\pi$-charges is set equal to zero for obvious reason. The decomposition of $V_{\mathrm{nn}}^{\sigma \pi}$ should in principle proceed analogously to that adopted for the mixed electronic term $V_{\mathrm{ee}}^{\sigma \pi}$. However, in view of the large difference in the $\sigma$ - and $\pi$-nuclear partial charges, the stockholder partitioning of the $V_{\mathrm{nn}}^{\sigma \pi}$ term is employed even for the EQP scheme. The equipartition of the $V_{\mathrm{nn}}^{\sigma \pi}$ term would lead to unrealistic results.

To this end it was implicitly assumed (i) that there is an unambiguous distinction between $\sigma$-and $\pi$-orbitals and (ii) that the $\sigma$ - and $\pi$-orbital interactions are relatively small compared to other terms.

Conceptually, the $\pi$ - and $\sigma$-orbitals are distinguished by means of the local symmetry with respect to the diatomic bond, as already expressed in the conventional chemical structure formulas of e.g. $\mathrm{CO}$ and $\mathrm{N}_{2}$ molecules. In polyatomic molecules the canonical HF orbitals are solutions of an eigenvalue problem, which allows for a strict $\sigma / \pi$ separation of delocalized MOs by the irreducible representations of the molecular point group, provided there is a plane of symmetry. In this case the local and molecular symmetries fall in line and strict $\sigma / \pi$ distinction of the molecular orbitals is guaranteed. Although small perturbations of the planar molecular fragment by a nonplanar substituent like e.g. the $\mathrm{CH}_{3}$ group in toluene can be treated within the same theoretical framework, strict $\sigma / \pi$ separability by symmetry is lost. In this particular example, however, it is still possible to assign individual MOs either to $\sigma$-or to $\pi$-orbital space in a meaningful way by enforcing the $C_{s}$ symmetry (vide infra). In general, a degree of delocalization of MOs depends solely on the Fock matrix elements and there is a gradual transition from the ideal $\sigma / \pi$ separation of orbitals to their strong mixing. Hence, in considering homodesmotic-like reaction energies, assignment of individual MOs of nonplanar molecules 
to $\pi$ - and $\sigma$-orbital space may give rise to considerable bias. Note that $\sigma / \pi$ orbital mixing may result from large coupling elements in the Fock matrix as well as from accidental neardegeneracy of the weakly interacting molecular substructures. It should be kept in mind that the concept of $\sigma / \pi$ separation is justified only in the latter case.

Finally, it should be recalled that the conventional $\pi$-electron theory invokes the $\sigma / \pi$ separability from the outset through a particular choice of Hamiltionian ${ }^{44}$ thus yielding the standard $\pi$-scheme (SPI). It implies that the mixed $V_{\mathrm{ee}}^{\sigma \pi}$ term is ascribed to the $\pi$-electron framework, while the nuclear repulsion energy is completely assigned to the $\sigma$-framework, which in our view is rather arbitrary. Hence, in the following we shall primarily refer to our preferred SHR partitioning scheme.

Notice that for molecules involved in homodesmotic reactions $1-7$ a strict $\sigma / \pi$ distinction is possible, because all systems are planar. Since molecules considered are at the optimized HF equilibrium geometries, the virial requirement ${ }^{45-47}$ was imposed on their HF energies. The numerical results of the energy partitioning analysis on HF/cc-pVDZ model are given in Table 1.

The first general conclusion to be drawn is that stability of compounds $\mathbf{1}-\mathbf{6}$ decreases upon $\mathrm{F}$ substitution from $\Delta E(\mathbf{1})=$ $-23.3 \mathrm{kcal} / \mathrm{mol}$ found for $\mathbf{1}$ to $\Delta E(\mathbf{6})=-16.3 \mathrm{kcal} / \mathrm{mol}$ in $\mathbf{6}$, although a decrease in $|\Delta E(\mathbf{n})|$ is not uniform. It should be also noted in passing that the HF/cc-pVTZ calculations do not change the general picture, although the actual numbers for different energy components are somewhat different.

Let us consider monofluorinated benzene $\mathbf{1}$ in greater detail now. Intuitively, a single fluorine substituent should not dramatically change aromaticity of benzene. This is indeed the case: the HF/cc-pVDZ [HF/cc-pVTZ] stabilization $\Delta E(\mathbf{1})$ is $-23.3[-24.5] \mathrm{kcal} / \mathrm{mol}$, being very close to those found in $\mathbf{B}$, $-23.9[-23.5] \mathrm{kcal} / \mathrm{mol}$. However, much to our surprise the energy component analysis shows that this result is due to the more favorable $\pi$-type interactions. Perusal of the numbers presented in Table 1 reveals that the stability of 1 relative to open chain polyenes given by eq 2 arises due to the enormously increased nuclear-electron attractions $\Delta V_{\text {ne }}^{\sigma}$ and $\Delta V_{\text {ne }}^{\pi}$ (in absolute value) for both $\sigma$ - and $\pi$-electrons. On the contrary, the $\Delta V_{\mathrm{ee}}^{\sigma}$ and $\Delta V_{\mathrm{nn}}^{\sigma}$ terms of the $\sigma$-framework become strongly destabilizing factors, which is diametrically opposite to the parent benzene case. This abrupt and dramatic change in the overall picture caused by single $\mathrm{F}$ substitution calls for caution. The question arises whether there is something wrong with the underlying system of homodesmotic reactions, or with the energy component analysis. This will be at the focus in the main body of the paper. It appears also that interpretation of the result obtained by eq 2 represents a fluctuation. Namely, in the rest of the substituted molecules $\mathbf{2}-\mathbf{6}$ the stabilization energy is a result of the more favorable $\sigma$-interactions due to a strongly pronounced preference of the $\Delta V_{\mathrm{ee}}^{\sigma}$ and $\Delta V_{\mathrm{nn}}^{\sigma}$ terms. In other words, a dramatic decrease in the $\sigma$-electron repulsions and in the $\sigma$-share of the nuclear repulsions leads to stabilization of the polyfluorinated benzenes relative to the corresponding zigzag fluorinated polyenes. It follows as a corollary that the system of eqs 1-7 does not exhibit a regular pattern in describing the fluorine substitution effect.

In view of the peculiar behavior of the monofluorinated benzene 1 compared to parent benzene, we tried several other homodesmotic reactions based on the open chain polyenes. However, the final conclusion was always the same: the stabilization was a consequence of the strong increase in the nuclear-electron attraction of both $\sigma$ - and $\pi$-electrons in $\mathbf{1}$, just like in the case of eq 2 leading to overall predominance of the $\pi$-interactions as a net result. Obviously, the linear open chain polyenes used as reference compounds cannot offer a consistent picture of the aromaticity in fluorosubstituted benzenes, which strongly indicates that the intramolecular interactions are not well balanced in homodesmotic reactions $1-7$. For example, the use of 3-fluorohexatriene and 4-fluorooctatetraene gave $\Delta E(\mathbf{1})^{\prime}$ and $\Delta E(\mathbf{1})^{\prime \prime}$ stabilization energies of -22.7 and -22.3 $\mathrm{kcal} / \mathrm{mol}$, respectively, at the HF/cc-pVTZ level with the same outcome of the energy partitioning analysis. An important clue in a pinpointing the reason behind a failure of eqs $1-7$ is given by Schleyer's protobranching concept, which is based on the 1,3-protobranching attractive interactions as a consequence of the electron density fluctuations (dispersion forces). ${ }^{48}$ It seems that imbalance of 1,3-interactions is the main cause of their inadequacy. In particular, the 1,3-interactions in trans-1,3butadiene involving $\mathrm{CH}_{2}$ groups in the products are not matched in the educts (i.e. benzene and ethylenes in eq 1 and their fluorinated derivatives in the remaining equations). It is also conceivable that the long-range nuclear repulsions of the $\mathrm{CH}_{2}$ in trans-1,3-butadiene and its monofluoro derivatives are not balanced in the left sides of eqs $1-7$.

Hence, alternative systems of specific homodesmotic reactions should be found, which are better suited for description of the aromatic stabilization. Our efforts in this directions are described in the next section.

3.2. Homostructural Reactions with Cyclic Polyenes. There are several systems of conceived reactions, which lend themselves as viable alternatives. Starting with the parent benzene, we shall examine eqs $11-13$, which were suggested by Schleyer and co-workers as better measures of aromaticity. ${ }^{49,50}$ Let us consider eq 11 first:

$$
\mathbf{B}+3(\mathbf{1 9})=3(\mathbf{2 0})+\mathbf{2 1}+\Delta E(\text { ease })_{\mathbf{B}}^{\prime}
$$

Here, 19, 20, and 21 stand for cyclohexene, 1,3-cyclohexadiene, and cyclohexane (Figure 2), respectively. The idea behind gedanken chemical reactions is that they are appropriately balanced so that the reaction energies almost solely represent the effect under scrutiny, while all other effects are canceled at least to a large extent. It is important to notice in this respect that eq 11 preserves the number of protobranching 1,3interactions, which is equal left and right. Moreover, the hyperconjugative interactions between the $\mathrm{CH}_{2}$ groups and $\pi$-bonds are balanced too.

This type of homodesmotic reaction was termed homomolecular by Chesnut and Davis ${ }^{51}$ meaning that the same ring structures left and right are involved. Hence, it is expected that the strain energy cancels to a great extent. Perhaps the name homostructural reactions would be more fitting. Namely, if the structures of educts and products are very similar, then a strong semblance in their density distributions and bonding can be expected. This does not mean that all features are exactly matched left and right, since in this case the equation would lose its meaning. A close examination of the type of chemical bonds of compounds entering eq 11 reveals that $6\left[\mathrm{C}\left(\mathrm{sp}^{2}\right)==\mathrm{C}\right.$ $\left.\left(\mathrm{sp}^{2}\right)\right]$ bonds of the benzene ring left, are compared with three essentially localized double $3\left[\mathrm{C}\left(\mathrm{sp}^{2}\right)=\mathrm{C}\left(\mathrm{sp}^{2}\right)\right]$ bonds on the right-hand side, which are accompanied by the $3\left[\mathrm{C}\left(\mathrm{sp}^{2}\right)-\mathrm{C}\left(\mathrm{sp}^{2}\right)\right]$ single bonds. The difference in energy $\Delta E$ (ease) $)_{\mathbf{B}}^{\prime}$ is exactly the feature we would like to examine and which is called aromaticity. Since the bond lengths of the benzene ring $d\left[\mathrm{C}\left(\mathrm{sp}^{2}\right)=-\mathrm{C}\left(\mathrm{sp}^{2}\right)\right]$ are different from $d\left[\mathrm{C}\left(\mathrm{sp}^{2}\right)-\mathrm{C}\left(\mathrm{sp}^{2}\right)\right]$ and $d\left[\mathrm{C}(\mathrm{sp})^{2}=\mathrm{C}(\mathrm{sp})^{2}\right]$, reaction 11 is not isostructural, but homostructural instead. 
TABLE 1: Scaled Values of $\sigma$ and $\pi$ Contributions to the Kinetic and Potential Parts of the $\Delta E_{\mathrm{HF}}^{\text {tot }}$ for Homodesmotic Reactions 1-7, Obtained at the HF/cc-pVDZ [HF/cc-pVTZ] Level of Theory (in kcal/mol)

\begin{tabular}{|c|c|c|c|c|c|c|c|c|c|c|c|}
\hline compd/(eq) & $\Delta T^{\sigma}$ & $\Delta T^{\pi}$ & $\Delta V_{\mathrm{ne}}^{\sigma}$ & $\Delta V_{\mathrm{ne}}^{\pi}$ & $\Delta V_{\mathrm{ee}}^{\sigma}$ & $\Delta V_{\mathrm{ee}}^{\pi}$ & $\Delta V_{\mathrm{nn}}^{\sigma}$ & $V_{\mathrm{nn}}^{\pi}$ & $\Delta E^{\sigma}$ & $\Delta E^{\pi}$ & $\Delta E^{\text {tot }}$ \\
\hline $\mathbf{B} /(1)$ & $\begin{array}{c}64.8 \\
{[71.3]}\end{array}$ & $\begin{array}{c}-41.0 \\
{[-47.9]}\end{array}$ & $\begin{array}{c}8960.3 \\
{[8976.1]}\end{array}$ & $\begin{array}{c}-192.3 \\
{[-181.3]}\end{array}$ & & & & & & & \\
\hline SHR & & & & & $\begin{array}{c}-4703.3 \\
{[-4718.0]}\end{array}$ & $\begin{array}{c}328.6 \\
{[329.9]}\end{array}$ & $\begin{array}{c}-4737.3 \\
{[-4751.1]}\end{array}$ & $\begin{array}{c}296.4 \\
{[297.5]}\end{array}$ & $\begin{array}{c}-415.5 \\
{[-421.5]}\end{array}$ & $\begin{array}{c}391.6 \\
{[391.6]}\end{array}$ & $\begin{array}{l}-23.9 \\
{[-23.5]}\end{array}$ \\
\hline EQP & & & & & $\begin{array}{c}-4492.4 \\
{[-4504.7]}\end{array}$ & $\begin{array}{c}117.7 \\
{[116.7]}\end{array}$ & $\begin{array}{c}-4737.3 \\
{[-4751.1]}\end{array}$ & $\begin{array}{c}296.4 \\
{[297.5]}\end{array}$ & $\begin{array}{c}-204.6 \\
{[-208.4]}\end{array}$ & $\begin{array}{c}180.7 \\
{[185.0]}\end{array}$ & $\begin{array}{l}-23.9 \\
{[-23.4]}\end{array}$ \\
\hline SPI & & & & & $\begin{array}{l}-4472.8 \\
{[-4483.3]}\end{array}$ & $\begin{array}{c}98.1 \\
{[95.2]}\end{array}$ & $\begin{array}{c}-4440.9 \\
{[-4453.6]}\end{array}$ & & $\begin{array}{c}111.3 \\
{[110.5]}\end{array}$ & $\begin{array}{c}-135.2 \\
{[-134.0]}\end{array}$ & $\begin{array}{l}-23.9 \\
{[-23.5]}\end{array}$ \\
\hline $1 /(2)$ & $\begin{array}{c}23.1 \\
{[18.1]}\end{array}$ & $\begin{array}{c}0.2 \\
{[6.3]}\end{array}$ & $\begin{array}{c}-1308.2 \\
{[-2534.8]}\end{array}$ & $\begin{array}{c}-3214.8 \\
{[-3421.7]}\end{array}$ & & & & & & & \\
\hline SHR & & & & & $\begin{array}{c}969.1 \\
{[1627.4]}\end{array}$ & $\begin{array}{c}1221.9 \\
{[1262.0]}\end{array}$ & $\begin{array}{c}1129.5 \\
{[1825.7]}\end{array}$ & $\begin{array}{c}1155.8 \\
{[1192.5]}\end{array}$ & $\begin{array}{c}813.5 \\
{[936.4]}\end{array}$ & $\begin{array}{c}-836.8 \\
{[-960.9]}\end{array}$ & $\begin{array}{c}-23.3 \\
{[-24.5]}\end{array}$ \\
\hline EQP & & & & & $\begin{array}{c}602.2 \\
{[1201.9]}\end{array}$ & $\begin{array}{c}1588.8 \\
{[1687.5]}\end{array}$ & $\begin{array}{c}1129.5 \\
{[1825.7]}\end{array}$ & $\begin{array}{c}1155.8 \\
{[1192.5]}\end{array}$ & $\begin{array}{c}446.6 \\
{[510.9]}\end{array}$ & $\begin{array}{l}-469.9 \\
{[-535.4]}\end{array}$ & $\begin{array}{l}-23.3 \\
{[-24.5]}\end{array}$ \\
\hline SPI & & & & & $\begin{array}{l}-542.8 \\
{[-27.4]}\end{array}$ & $\begin{array}{c}2733.8 \\
{[2916.8]}\end{array}$ & $\begin{array}{c}2285.3 \\
{[3018.2]}\end{array}$ & & $\begin{array}{c}457.5 \\
{[474.1]}\end{array}$ & $\begin{array}{c}-480.8 \\
{[-498.6]}\end{array}$ & $\begin{array}{l}-23.3 \\
{[-24.5]}\end{array}$ \\
\hline $2 /(3)$ & $\begin{array}{c}50.3 \\
{[40.4]}\end{array}$ & $\begin{array}{c}-26.5 \\
{[-16.2]}\end{array}$ & $\begin{array}{c}16487.2 \\
{[15907.6]}\end{array}$ & $\begin{array}{c}1150.7 \\
{[1008.6]}\end{array}$ & & & & & & & \\
\hline SHR & & & & & $\begin{array}{c}-9253.8 \\
{[-8927.1]}\end{array}$ & $\begin{array}{c}367.7 \\
{[399.8]}\end{array}$ & $\begin{array}{c}-9000.7 \\
{[-8657.7]}\end{array}$ & $\begin{array}{c}201.4 \\
{[220.2]}\end{array}$ & $\begin{array}{c}-1717.2 \\
{[-1636.7]}\end{array}$ & $\begin{array}{c}1693.4 \\
{[1612.5]}\end{array}$ & $\begin{array}{c}-23.8 \\
{[-24.3]}\end{array}$ \\
\hline EQP & & & & & $\begin{array}{c}-8306.7 \\
{[-8015.0]}\end{array}$ & $\begin{array}{c}-579.3 \\
{[-512.4]}\end{array}$ & $\begin{array}{l}-9000.7 \\
{[-8657.7]}\end{array}$ & $\begin{array}{c}201.4 \\
{[220.2]}\end{array}$ & $\begin{array}{c}-770.1 \\
{[-724.6]}\end{array}$ & $\begin{array}{c}746.3 \\
{[700.3]}\end{array}$ & $\begin{array}{l}-23.8 \\
{[-24.3]}\end{array}$ \\
\hline SPI & & & & & $\begin{array}{c}-7664.9 \\
{[-7426.6]}\end{array}$ & $\begin{array}{l}-1221.1 \\
-1100.7]\end{array}$ & $\begin{array}{c}-8799.4 \\
{[-8437.5]}\end{array}$ & & $\begin{array}{c}73.0 \\
{[84.0]}\end{array}$ & $\begin{array}{c}-96.8 \\
{[-108.2]}\end{array}$ & $\begin{array}{c}-23.8 \\
{[-24.3]}\end{array}$ \\
\hline $3 /(4)$ & $\begin{array}{c}64.6 \\
{[61.9]}\end{array}$ & $\begin{array}{c}-43.9 \\
{[-40.8]}\end{array}$ & $\begin{array}{c}18837.1 \\
{[18859.6]}\end{array}$ & $\begin{array}{c}1392.4 \\
{[1347.4]}\end{array}$ & & & & & & & \\
\hline SHR & & & & & $\begin{array}{c}-10563.9 \\
{[-10563.1]}\end{array}$ & $\begin{array}{c}393.2 \\
{[409.2]}\end{array}$ & $\begin{array}{c}-10330.4 \\
{[-10328.6]}\end{array}$ & $\begin{array}{c}230.4 \\
{[233.2]}\end{array}$ & $\begin{array}{c}-1992.8 \\
{[-1970.1]}\end{array}$ & $\begin{array}{c}1972.1 \\
{[1949.0]}\end{array}$ & $\begin{array}{c}-20.7 \\
{[-21.1]}\end{array}$ \\
\hline EQP & & & & & $\begin{array}{c}-9485.9 \\
{[-9492.0]}\end{array}$ & $\begin{array}{c}-684.8 \\
{[-661.9]}\end{array}$ & $\begin{array}{c}-10330.4 \\
{[-10328.6]}\end{array}$ & $\begin{array}{c}230.4 \\
{[233.2]}\end{array}$ & $\begin{array}{c}-914.7 \\
{[-899.0]}\end{array}$ & $\begin{array}{c}894.0 \\
{[877.8]}\end{array}$ & $\begin{array}{c}-20.7 \\
{[-21.1]}\end{array}$ \\
\hline SPI & & & & & $\begin{array}{c}-8708.3 \\
{[-8729.8]}\end{array}$ & $\begin{array}{c}-1462.3 \\
{[-1424.1]}\end{array}$ & $\begin{array}{c}-10099.9 \\
{[-10095.4]}\end{array}$ & & $\begin{array}{c}93.2 \\
{[96.4]}\end{array}$ & $\begin{array}{c}-113.9 \\
{[-117.5]}\end{array}$ & $\begin{array}{l}-20.7 \\
{[-21.1]}\end{array}$ \\
\hline $4 /(5)$ & $\begin{array}{c}51.6 \\
{[41.3]}\end{array}$ & $\begin{array}{c}-32.2 \\
{[-21.2]}\end{array}$ & $\begin{array}{c}23333.6 \\
{[23348.5]}\end{array}$ & $\begin{array}{c}2248.2 \\
{[2159.9]}\end{array}$ & & & & & & & \\
\hline SHR & & & & & $\begin{array}{c}-13260.3 \\
{[-13237.6]}\end{array}$ & $\begin{array}{c}362.3 \\
{[389.39]}\end{array}$ & $\begin{array}{c}-12864.6 \\
{[-12846.5]}\end{array}$ & $\begin{array}{c}142.0 \\
{[145.6]}\end{array}$ & $\begin{array}{c}-2739.7 \\
{[-2693.3]}\end{array}$ & $\begin{array}{c}2720.3 \\
{[2674.2]}\end{array}$ & $\begin{array}{c}-19.4 \\
{[-20.1]}\end{array}$ \\
\hline EQP & & & & & $\begin{array}{c}-11767.5 \\
{[-11759.3]}\end{array}$ & $\begin{array}{r}-1130.6 \\
{[-1088.4}\end{array}$ & $\begin{array}{c}-12864.6 \\
{[-12846.5]}\end{array}$ & $\begin{array}{l}142.0 \\
{[145.6]}\end{array}$ & $\begin{array}{l}-1246.8 \\
{[-1216.1]}\end{array}$ & $\begin{array}{c}1227.4 \\
{[1195.9]}\end{array}$ & $\begin{array}{l}-19.4 \\
{[-20.1]}\end{array}$ \\
\hline SPI & & & & & $\begin{array}{c}-10603.3 \\
{[-10623.7]}\end{array}$ & $\begin{array}{l}-2294.8 \\
{[-2224.0]}\end{array}$ & $\begin{array}{l}-12722.4 \\
{[-12700.9]}\end{array}$ & & $\begin{array}{c}59.4 \\
{[65.1]}\end{array}$ & $\begin{array}{c}-78.8 \\
{[-85.2]}\end{array}$ & $\begin{array}{l}-19.4 \\
{[-20.1]}\end{array}$ \\
\hline $5 /(6)$ & $\begin{array}{c}42.6 \\
{[39.1]}\end{array}$ & $\begin{array}{c}-27.0 \\
{[-21.9]}\end{array}$ & $\begin{array}{c}26148.7 \\
{[26196.8]}\end{array}$ & $\begin{array}{c}2583.9 \\
{[2524.0]}\end{array}$ & & & & & & & \\
\hline SHR & & & & & $\begin{array}{c}-14351.8 \\
{[-14582.1]}\end{array}$ & $\begin{array}{c}66.7 \\
{[118.3]}\end{array}$ & $\begin{array}{c}-14575.8 \\
{[-14358.9]}\end{array}$ & $\begin{array}{c}97.6 \\
{[67.3]}\end{array}$ & $\begin{array}{c}-2736.8 \\
{[-2705.0]}\end{array}$ & $\begin{array}{c}2721.2 \\
{[2687.8]}\end{array}$ & $\begin{array}{l}-15.6 \\
{[-17.2]}\end{array}$ \\
\hline EQP & & & & & $\begin{array}{c}-13177.2 \\
{[-13192.6]}\end{array}$ & $\begin{array}{c}-1301.0 \\
{[-1271.1]}\end{array}$ & $\begin{array}{l}-14351.8 \\
{[-14358.9]}\end{array}$ & $\begin{array}{c}66.7 \\
{[67.3]}\end{array}$ & $\begin{array}{c}-1338.1 \\
{[-1315.5]}\end{array}$ & $\begin{array}{c}1322.5 \\
{[1298.3]}\end{array}$ & $\begin{array}{c}-15.6 \\
{[-17.2]}\end{array}$ \\
\hline SPI & & & & & $\begin{array}{l}-11828.8 \\
{[-11863.8]}\end{array}$ & $\begin{array}{c}-2649.4 \\
{[-2600.0]}\end{array}$ & $\begin{array}{l}-14285.1 \\
{[-14291.6]}\end{array}$ & & $\begin{array}{c}76.9 \\
{[80.6]}\end{array}$ & $\begin{array}{c}-92.5 \\
{[-97.8]}\end{array}$ & $\begin{array}{l}-15.6 \\
{[-17.2]}\end{array}$ \\
\hline $6 /(7)$ & $\begin{array}{c}-126.8 \\
{[-129.3]}\end{array}$ & $\begin{array}{c}143.1 \\
{[150.3]}\end{array}$ & $\begin{array}{c}219078.7 \\
{[219271.2]}\end{array}$ & $\begin{array}{c}57921.2 \\
{[57881.5]}\end{array}$ & & & & & & & \\
\hline SHR & & & & & $\begin{array}{l}-122815.8 \\
-122925.4]\end{array}$ & $\begin{array}{c}-15705.4 \\
{[-15697.1]}\end{array}$ & $\begin{array}{c}-122640.7 \\
{[-122692.0]}\end{array}$ & $\begin{array}{c}-15870.6 \\
{[-15880.0]}\end{array}$ & $\begin{array}{c}-26504.6 \\
{[-26475.6]}\end{array}$ & $\begin{array}{c}26488.3 \\
{[26454.7]}\end{array}$ & $\begin{array}{c}-16.3 \\
{[-20.9]}\end{array}$ \\
\hline EQP & & & & & $\begin{array}{c}-109479.6 \\
{[-109593.3]}\end{array}$ & $\begin{array}{c}-29041.6 \\
{[-29029.3]}\end{array}$ & $\begin{array}{c}-122640.7 \\
{[-122692.0]}\end{array}$ & $\begin{array}{c}-15870.6 \\
{[-15880.0]}\end{array}$ & $\begin{array}{c}-13168.5 \\
{[-13143.4]}\end{array}$ & $\begin{array}{c}13152.1 \\
{[13122.5]}\end{array}$ & $\begin{array}{l}-16.3 \\
{[-20.9]}\end{array}$ \\
\hline SPI & & & & & $\begin{array}{c}-86494.2 \\
{[-86612.6]}\end{array}$ & $\begin{array}{l}-52026.9 \\
{[-52010.0]}\end{array}$ & $\begin{array}{c}-138511.3 \\
{[-138572.0]}\end{array}$ & & $\begin{array}{c}-6053.6 \\
{[-6042.7]}\end{array}$ & $\begin{array}{c}6037.3 \\
{[6021.8]}\end{array}$ & $\begin{array}{l}-16.3 \\
{[-20.9]}\end{array}$ \\
\hline
\end{tabular}

There are two ways in which eq 11 can be employed. The first is to optimize all structures of the compounds involved. This has a serious drawback that the $\pi$ AOs in $\mathbf{1 9}$ and $\mathbf{2 0}$ mix considerably with the $\sigma \mathrm{CC}$ AOs due to nonplanarity and the $\sigma / \pi$ separation is not possible even at the initial orbital level. In order to overcome the $\sigma / \pi$ separability problem in nonplanar molecules as much as possible, compounds 19, 20, and 21 are artificially constrained to conform to planar symmetry (point group $C_{s}$ ) by placing the heavy atoms in the symmetry plane. The number of their electrons contributing to the $\sigma$ - and $\pi$-frameworks is given by the number of occupied atomic orbitals of $a^{\prime}$ and $a^{\prime \prime}$ symmetry, respectively. Here the single and double prime denote symmetric and antisymmetric behavior of the heavy atom AOs upon reflection in the symmetry plane, respectively. Similarly, the linear combination of the out of plane $\mathrm{H}$ atom AOs $a^{\prime}$ and $a^{\prime \prime}$ can be constructed. Relying on the common sense, the positive partial nuclear charge assigned to the $\sigma$ - and $\pi$-frameworks of a particular heavy atom equals the corresponding numbers of the $\sigma$ - and $\pi$-electrons in the conceived initial promolecule picture. ${ }^{40}$ Hence, for the heavy 
<smiles>C1=CCCCC1</smiles>

19

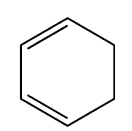

20

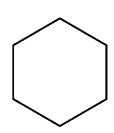

21<smiles>FC1=CCCC=C1</smiles>

22

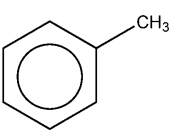

toluene

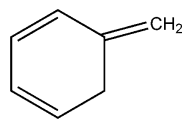

5-methylene-1,3-cyclohexadiene

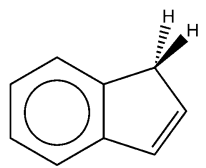

indene

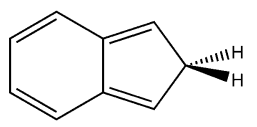

isoindene

Figure 2. Schematic representation of molecules participating in homostructural reactions.

atoms placed in the molecular plane it is equal to the conventional partitioning outlined above. The nuclear charge of hydrogens, located in the out of plane $\mathrm{CH}_{2}$ groups e.g. in cyclohexadiene or cyclohexane, is equipartitioned between the $\sigma$ - and $\pi$-frameworks, $Z(\mathrm{H})^{\pi}=Z(\mathrm{H})^{\sigma}=0.5$. The reason is that the $1 \mathrm{~s}\left(\mathrm{H}_{1}\right)$ and $1 \mathrm{~s}\left(\mathrm{H}_{2}\right)$ AOs of the $\mathrm{CH}_{2}$ group form symmetric and antisymmetric $1 \mathrm{~s}\left(\mathrm{H}_{1}\right)+1 \mathrm{~s}\left(\mathrm{H}_{2}\right)$ and $1 \mathrm{~s}\left(\mathrm{H}_{1}\right)-1 \mathrm{~s}\left(\mathrm{H}_{2}\right)$ combinations, respectively, which belong to the $\sigma$ - and $\pi$-systems accordingly. Consequently, each hydrogen nucleus contributes $1 / 2$ of the proton charge to the $\sigma$ - and $\pi$-frameworks. Evidently, this procedure results in artificial contributions of the $\sigma$-bonds $\left(\mathrm{C}-\mathrm{H}\right.$ bonds of the $\mathrm{CH}_{2}$ groups) to the $\pi$-space. Hence, this model is not applicable to an isolated molecule. However, it is quite useful in analyzing energies of the homodesmotic reactions provided the amount of the $\sigma$-contributions to the $\pi$-space remains (approximately) constant in educts and products. It should be mentioned that the use of artificial planar structures for 19, 20, and 21 compounds involved in eq 11 not only allows for the $\sigma / \pi$ separation of MOs in a sense that they can be distinguished by symmetry but also ensures that the results are invariant to the orthogonal transformations within the $\sigma$ - and $\pi$-MO manifolds. This is an advantage enabled by the theoretical modeling, and it is acceptable as long as the model homostructural reaction 11 has well balanced interactions between the $\mathrm{CH}_{2}$ groups themselves and with the $\pi$ bonds in the educts and products. Importantly, the latter implies that the number of hyperconjugative interactions in eq 11 is balanced and cancels out.

Another possibility is offered by Schleyer's idea of isomerization: ${ }^{49}$

toluene $=5$-methylene-1,3-cyclohexadiene $+\Delta E(12)$

Here, the $\Delta E(12)$ of toluene should be practically identical to that of benzene (apart from hyperconjugation of the $\mathrm{CH}_{3}$ group) being measured against the 5-methylene-1,3-cyclohexadiene isomer (Figure 2). It should be mentioned that toluene in our model calculation is forced to assume $C_{s}$ symmetry (i.e. one $\mathrm{C}-\mathrm{H}$ bond from methyl group is in the plane of benzene ring). In this way we do not only enable a reasonable $\sigma / \pi$ separation, but also mimick much better the $\mathrm{CH}_{2}$ group in 5-methylene1,3-cyclohexadiene.

A more recent suggestion is given by the isomerization stabilization energy (ISE) of the indene-isoindene isomers (Figure 2): ${ }^{50}$

$$
\text { indene }=\text { isoindene }+\Delta E(13)
$$

The structural similarities between indene and isoindene are obvious.

Finally, it should be mentioned that the aromatic stabilization of $\mathbf{B}$, estimated by eqs 11,12 , and 13 , is extrinsic aromaticity, since the topology of the $\pi$-electron network is changed in the course of reaction. It is obvious that the energies derived from equations including model compounds in nonequilibrium geometries were not constrained to satisfy virial theorem.

Inspection of eqs 11,12 , and 13 shows that only the first one enables sequential fluorination of benzene ending up in hexafluorobenzene. This is not possible for toluene and indene involved in eqs 12 and 13. Consequently, the latter two equations will be only briefly considered here deferring a detailed discussion of the fluorosubstituted derivatives to one of the forthcoming papers. The aromatic stabilization of the benzene moiety according to eqs 12 and 13 is $\Delta E(12)=-35.1[-34.3]$ $\mathrm{kcal} / \mathrm{mol}$ and $\Delta E(13)=-26.9[-26.6] \mathrm{kcal} / \mathrm{mol}$, respectively, as obtained by the HF/cc-pVDZ//MP2(fc)/cc-pVDZ [HF/cc$\mathrm{pVTZ//MP2(fc)/cc-pVTZ]} \mathrm{model.} \mathrm{These} \mathrm{results} \mathrm{are} \mathrm{comparable}$ to that obtained by eq 11 (vide infra). An important outcome of the energy component analysis of the energies $\Delta E(12)$ and $\Delta E(13)$ is that in both cases aromaticity is a consequence of the more favorable $\pi$-framework.

Let us consider results obtained by eq 11 . They are presented in Table 2. It appears that the aromatic stabilization of benzene obtained by the HF/cc-pVDZ [HF/cc-pVTZ] model is -38.3 [-37.9] kcal/mol. It compares with the HF/cc-pVDZ [HF/ccpVTZ] result of $-36.1[-35.4] \mathrm{kcal} / \mathrm{mol}$ obtained with full optimization of geometries of molecules entering eq 11 . Obviously, the planar model is reliable, possessing some conceptual and interpretive advantages at the same time. Additional support to the planar model will be given in section 3.3. An interesting digression is given by comparison of the $\Delta E$ (ease) of benzene, obtained by eq 1 , corrected by a difference in energy between optimized cis- and trans-1,3-butadiene. It appears that the trans conformation is more stable than the cis by $-3.3[-3.4] \mathrm{kcal} / \mathrm{mol}$, as obtained by the HF/cc-pVDZ [HF/ cc-pVTZ] model. Therefore, the corrected values $\Delta E$ (ease) of B are $-33.8[-33.7] \mathrm{kcal} / \mathrm{mol}$, which is in good accordance with numbers $-36.1[-35.4] \mathrm{kcal} / \mathrm{mol}$, derived from eq 11 based on optimized cyclic cyclohexene and cyclohexadiene. Obviously, cis-1,3-butadiene would be a better model than the trans conformation in eq 1 . The problem is that it is nonplanar, thus preventing a clear distinction between the $\sigma$ and $\pi$ AOs and MOs. An important advantage of the compounds 19, 20, and 21 is that the $\sigma / \pi$ separation of orbitals is possible, if they are considered in the enforced $C_{s}$ symmetry. Additionally, 20 does involve planar the cis conformation of 1,3-butadiene.

The energy component analysis reveals that aromatic stabilization occurs due to a combined action of the $\sigma$ - and $\pi$-electron frameworks. More specifically, $\Delta E^{\sigma}$ and $\Delta E^{\pi}$ components assume $-23.7[-14.8]$ and $-14.6[-23.1] \mathrm{kcal} / \mathrm{mol}$, respectively, according to the SHR recipe, where results are obtained by the HF model employing the cc-pVDZ and cc-pVTZ basis sets, the latter being within square brackets. This illustrates the 
TABLE 2: Values of $\sigma$ and $\pi$ Contributions to the Kinetic and Potential Energy Parts of the Change in Total Energy $\Delta E_{\mathrm{HF}}^{\text {tot }}$ for Reactions 11 and 14-19, Obtained at the HF/cc-pVDZ [HF/cc-pVTZ] Level of Theory (in kcal/mol)

\begin{tabular}{|c|c|c|c|c|c|c|c|c|c|c|c|}
\hline $\operatorname{compd} /(\mathrm{eq})$ & $\Delta T^{\sigma}$ & $\Delta T^{\pi}$ & $\Delta V_{\mathrm{ne}}^{\sigma}$ & $\Delta V_{\mathrm{ne}}^{\pi}$ & $\Delta V_{\mathrm{ee}}^{\sigma}$ & $\Delta V_{\mathrm{ee}}^{\pi}$ & $\Delta V_{\mathrm{nn}}^{\sigma}$ & $\Delta V_{\mathrm{nn}}^{\pi}$ & $\Delta E^{\sigma}$ & $\Delta E^{\pi}$ & $\Delta E^{\text {tot }}$ \\
\hline $\mathbf{B} /(11)$ & $\begin{array}{c}154.6 \\
{[167.2]}\end{array}$ & $\begin{array}{c}-122.1 \\
{[-128.0]}\end{array}$ & $\begin{array}{c}-3055.0 \\
{[-3159.8]}\end{array}$ & $\begin{array}{c}-289.7 \\
{[-304.1]}\end{array}$ & & & & & & & \\
\hline SHR & & & & & $\begin{array}{c}1412.2 \\
{[1462.9]}\end{array}$ & $\begin{array}{c}188.5 \\
{[195.7]}\end{array}$ & $\begin{array}{c}1464.6 \\
{[1514.9]}\end{array}$ & $\begin{array}{c}208.7 \\
{[213.3]}\end{array}$ & $\begin{array}{c}-23.7 \\
{[-14.8]}\end{array}$ & $\begin{array}{c}-14.6 \\
{[-23.1]}\end{array}$ & $\begin{array}{c}-38.3 \\
{[-37.9]}\end{array}$ \\
\hline EQP & & & & & $\begin{array}{c}1402.3 \\
{[1448.5]}\end{array}$ & $\begin{array}{c}198.3 \\
{[210.2]}\end{array}$ & $\begin{array}{c}1464.6 \\
{[1514.9]}\end{array}$ & $\begin{array}{c}208.7 \\
{[213.3]}\end{array}$ & $\begin{array}{c}-33.5 \\
{[-29.2]}\end{array}$ & $\begin{array}{c}-4.7 \\
{[-8.6]}\end{array}$ & $\begin{array}{c}-38.3 \\
{[-37.9]}\end{array}$ \\
\hline SPI & & & & & $\begin{array}{c}1253.1 \\
{[1291.3]}\end{array}$ & $\begin{array}{c}347.5 \\
{[367.3]}\end{array}$ & $\begin{array}{c}1673.3 \\
{[1728.2]}\end{array}$ & & $\begin{array}{c}25.9 \\
{[26.9]}\end{array}$ & $\begin{array}{c}-64.2 \\
{[-64.8]}\end{array}$ & $\begin{array}{c}-38.3 \\
{[-37.9]}\end{array}$ \\
\hline $\mathbf{1} /(14)$ & $\begin{array}{c}1.3 \\
{[-0.4]}\end{array}$ & $\begin{array}{c}-3.0 \\
{[-2.0]}\end{array}$ & $\begin{array}{c}523.9 \\
{[520.9]}\end{array}$ & $\begin{array}{c}1405.7 \\
{[1401.4]}\end{array}$ & & & & & & & \\
\hline SHR & & & & & $\begin{array}{l}-10.9 \\
{[-2.4]}\end{array}$ & $\begin{array}{c}-982.2 \\
{[-985.6]}\end{array}$ & $\begin{array}{c}-175.0 \\
{[-140.9]}\end{array}$ & $\begin{array}{c}-759.1 \\
{[-790.3]}\end{array}$ & $\begin{array}{c}339.3 \\
{[377.3]}\end{array}$ & $\begin{array}{c}-338.7 \\
{[-376.5]}\end{array}$ & $\begin{array}{c}0.6 \\
{[0.8]}\end{array}$ \\
\hline EQP & & & & & $\begin{array}{c}-290.5 \\
{[-286.8]}\end{array}$ & $\begin{array}{c}-702.6 \\
{[-701.2]}\end{array}$ & $\begin{array}{c}-175.0 \\
{[-140.9]}\end{array}$ & $\begin{array}{c}-759.1 \\
{[-790.3]}\end{array}$ & $\begin{array}{c}59.7 \\
{[92.9]}\end{array}$ & $\begin{array}{c}-59.1 \\
{[-92.1]}\end{array}$ & $\begin{array}{c}0.6 \\
{[0.8]}\end{array}$ \\
\hline SPI & & & & & $\begin{array}{c}113.2 \\
{[114.0]}\end{array}$ & $\begin{array}{c}-1106.3 \\
{[-1102.0]}\end{array}$ & $\begin{array}{c}-934.2 \\
{[-931.2]}\end{array}$ & & $\begin{array}{c}-295.7 \\
{[-296.7]}\end{array}$ & $\begin{array}{c}296.4 \\
{[297.5]}\end{array}$ & $\begin{array}{c}0.6 \\
{[0.8]}\end{array}$ \\
\hline $2 /(15)$ & $\begin{array}{c}-27.6 \\
{[-28.7]}\end{array}$ & $\begin{array}{c}23.5 \\
{[19.8]}\end{array}$ & $\begin{array}{c}-10459.4 \\
{[-10433.6]}\end{array}$ & $\begin{array}{c}-1190.9 \\
{[-1183.6]}\end{array}$ & & & & & & & \\
\hline SHR & & & & & $\begin{array}{c}6334.0 \\
{[6330.8]}\end{array}$ & $\begin{array}{c}-613.0 \\
{[-619.3]}\end{array}$ & $\begin{array}{c}6263.6 \\
{[6307.6]}\end{array}$ & $\begin{array}{c}-323.8 \\
{[-386.8]}\end{array}$ & $\begin{array}{c}2110.6 \\
{[2176.1]}\end{array}$ & $\begin{array}{c}-2104.2 \\
{[-2169.8]}\end{array}$ & $\begin{array}{c}6.4 \\
{[6.3]}\end{array}$ \\
\hline EQP & & & & & $\begin{array}{c}5152.7 \\
{[5144.9]}\end{array}$ & $\begin{array}{c}568.2 \\
{[566.5]}\end{array}$ & $\begin{array}{c}6263.6 \\
{[6307.6]}\end{array}$ & $\begin{array}{c}-323.8 \\
{[-386.8]}\end{array}$ & $\begin{array}{c}929.3 \\
{[990.3]}\end{array}$ & $\begin{array}{c}-923.0 \\
{[-984.0]}\end{array}$ & $\begin{array}{c}6.4 \\
{[6.3]}\end{array}$ \\
\hline SPI & & & & & $\begin{array}{c}4488.2 \\
{[4479.3]}\end{array}$ & $\begin{array}{c}1232.7 \\
{[1232.2]}\end{array}$ & $\begin{array}{c}5939.8 \\
{[5920.9]}\end{array}$ & & $\begin{array}{c}-58.9 \\
{[-62.1]}\end{array}$ & $\begin{array}{c}65.3 \\
{[68.4]}\end{array}$ & $\begin{array}{c}6.4 \\
{[6.3]}\end{array}$ \\
\hline $3 /(16)$ & $\begin{array}{c}-47.1 \\
{[-46.7]}\end{array}$ & $\begin{array}{c}41.1 \\
{[30.7]}\end{array}$ & $\begin{array}{c}-28347.5 \\
{[-28311.4]}\end{array}$ & $\begin{array}{c}-6129.8 \\
{[-6119.3]}\end{array}$ & & & & & & & \\
\hline SHR & & & & & $\begin{array}{c}16359.6 \\
{[16357.7]}\end{array}$ & $\begin{array}{c}641.5 \\
{[637.2]}\end{array}$ & $\begin{array}{c}16595.6 \\
{[16657.4]}\end{array}$ & $\begin{array}{c}899.2 \\
{[806.4]}\end{array}$ & $\begin{array}{c}4560.6 \\
{[4657.0]}\end{array}$ & $\begin{array}{c}-4548.0 \\
{[-4644.9]}\end{array}$ & $\begin{array}{c}12.6 \\
{[12.1]}\end{array}$ \\
\hline EQP & & & & & $\begin{array}{c}14000.0 \\
{[13992.5]}\end{array}$ & $\begin{array}{c}3001.1 \\
{[3002.4]}\end{array}$ & $\begin{array}{c}16595.6 \\
{[16657.4]}\end{array}$ & $\begin{array}{c}899.2 \\
{[806.4]}\end{array}$ & $\begin{array}{c}2201.1 \\
{[2291.8]}\end{array}$ & $\begin{array}{c}-2188.5 \\
{[-2279.7]}\end{array}$ & $\begin{array}{c}12.6 \\
{[12.1]}\end{array}$ \\
\hline SPI & & & & & $\begin{array}{c}11403.0 \\
{[11392.5]}\end{array}$ & $\begin{array}{c}5598.1 \\
{[5602.4]}\end{array}$ & $\begin{array}{c}17494.8 \\
{[17463.8]}\end{array}$ & & $\begin{array}{c}503.2 \\
{[498.2]}\end{array}$ & $\begin{array}{c}-490.6 \\
{[-486.1]}\end{array}$ & $\begin{array}{c}12.6 \\
{[12.1]}\end{array}$ \\
\hline $4 /(17)$ & $\begin{array}{c}-89.5 \\
{[-90.1]}\end{array}$ & $\begin{array}{c}81.1 \\
{[65.9]}\end{array}$ & $\begin{array}{c}-51745.9 \\
{[-51691.1]}\end{array}$ & $\begin{array}{c}-13103.4 \\
{[-13109.2]}\end{array}$ & & & & & & & \\
\hline SHR & & & & & $\begin{array}{c}29378.7 \\
{[29383.1]}\end{array}$ & $\begin{array}{c}2646.7 \\
{[2651.7]}\end{array}$ & $\begin{array}{c}30071.1 \\
{[30149.3]}\end{array}$ & $\begin{array}{c}2781.4 \\
{[2659.7]}\end{array}$ & $\begin{array}{c}7614.4 \\
{[7751.2]}\end{array}$ & $\begin{array}{c}-7594.2 \\
{[-7731.9]}\end{array}$ & $\begin{array}{c}20.2 \\
{[19.3]}\end{array}$ \\
\hline EQP & & & & & $\begin{array}{c}25593.4 \\
{[25588.1]}\end{array}$ & $\begin{array}{c}6432.0 \\
{[6446.7]}\end{array}$ & $\begin{array}{c}30071.1 \\
{[30149.3]}\end{array}$ & $\begin{array}{c}2781.4 \\
{[2659.7]}\end{array}$ & $\begin{array}{c}3829.1 \\
{[3956.2]}\end{array}$ & $\begin{array}{c}-3808.9 \\
{[-3937.0]}\end{array}$ & $\begin{array}{c}20.2 \\
{[19.3]}\end{array}$ \\
\hline SPI & & & & & $\begin{array}{c}20327.9 \\
{[20311.8]}\end{array}$ & $\begin{array}{c}11697.5 \\
{[11723.0]}\end{array}$ & $\begin{array}{c}32852.5 \\
{[32809.0]}\end{array}$ & & $\begin{array}{l}1345.0 \\
{[139.6]}\end{array}$ & $\begin{array}{c}-1324.8 \\
{[-1320.3]}\end{array}$ & $\begin{array}{c}20.2 \\
{[19.3]}\end{array}$ \\
\hline $\mathbf{5} /(18)$ & $\begin{array}{c}-123.0 \\
{[-123.3]}\end{array}$ & $\begin{array}{l}112.2 \\
{[89.9]}\end{array}$ & $\begin{array}{c}-81991.9 \\
{[-81924.4]}\end{array}$ & $\begin{array}{c}-22411.4 \\
{[-22442.5]}\end{array}$ & & & & & & & \\
\hline SHR & & & & & $\begin{array}{c}46133.1 \\
{[46160.0]}\end{array}$ & $\begin{array}{c}5451.6 \\
{[5470.8]}\end{array}$ & $\begin{array}{c}47443.9 \\
{[47548.7]}\end{array}$ & $\begin{array}{c}5413.8 \\
{[5265.6]}\end{array}$ & $\begin{array}{c}11462.1 \\
{[11643.0]}\end{array}$ & $\begin{array}{c}-11433.8 \\
{[-11616.2]}\end{array}$ & $\begin{array}{c}28.3 \\
{[26.9]}\end{array}$ \\
\hline EQP & & & & & $\begin{array}{c}40563.5 \\
{[40574.9]}\end{array}$ & $\begin{array}{c}11021.2 \\
{[11055.9]}\end{array}$ & $\begin{array}{c}47443.9 \\
{[47548.7]}\end{array}$ & $\begin{array}{c}5413.8 \\
{[5265.6]}\end{array}$ & $\begin{array}{c}5892.5 \\
{[6058.0]}\end{array}$ & $\begin{array}{c}-5864.2 \\
{[-6031.1]}\end{array}$ & $\begin{array}{c}28.3 \\
{[26.9]}\end{array}$ \\
\hline SPI & & & & & $\begin{array}{c}31769.0 \\
{[31757.7]}\end{array}$ & $\begin{array}{c}19815.8 \\
{[19873.2]}\end{array}$ & $\begin{array}{c}52857.6 \\
{[52814.4]}\end{array}$ & & $\begin{array}{c}2511.7 \\
{[2506.3]}\end{array}$ & $\begin{array}{l}-2483.4 \\
{[-2479.5]}\end{array}$ & $\begin{array}{c}28.3 \\
{[26.9]}\end{array}$ \\
\hline $6 /(19)$ & $\begin{array}{c}-187.9 \\
{[-186.5]}\end{array}$ & $\begin{array}{c}174.5 \\
{[140.4]}\end{array}$ & $\begin{array}{c}-123600.1 \\
{[-123506.0]}\end{array}$ & $\begin{array}{c}-35683.2 \\
{[-35716.9]}\end{array}$ & & & & & & & \\
\hline SHR & & & & & $\begin{array}{c}69293.6 \\
{[69314.1]}\end{array}$ & $\begin{array}{c}9476.2 \\
{[9506.3]}\end{array}$ & $\begin{array}{c}71346.6 \\
{[71443.7]}\end{array}$ & $\begin{array}{c}9221.8 \\
{[9043.9]}\end{array}$ & $\begin{array}{c}16852.1 \\
{[17065.3]}\end{array}$ & $\begin{array}{c}-16810.7 \\
{[-17026.4]}\end{array}$ & $\begin{array}{c}41.4 \\
{[39.0]}\end{array}$ \\
\hline EQP & & & & & $\begin{array}{c}61203.6 \\
{[61207.7]}\end{array}$ & $\begin{array}{c}17566.2 \\
{[17612.6]}\end{array}$ & $\begin{array}{c}71346.6 \\
{[71443.7]}\end{array}$ & $\begin{array}{c}9221.8 \\
{[9043.9]}\end{array}$ & $\begin{array}{c}8762.1 \\
{[8959.0]}\end{array}$ & $\begin{array}{c}-8762.1 \\
{[-8920.1]}\end{array}$ & $\begin{array}{c}41.4 \\
{[39.0]}\end{array}$ \\
\hline SPI & & & & & $\begin{array}{c}47422.2 \\
{[47399.1]}\end{array}$ & $\begin{array}{c}31347.6 \\
{[31421.3]}\end{array}$ & $\begin{array}{c}80568.3 \\
{[80568.3]}\end{array}$ & & $\begin{array}{c}4202.5 \\
{[4194.2]}\end{array}$ & $\begin{array}{c}-4161.1 \\
{[-4155.3]}\end{array}$ & $\begin{array}{c}41.4 \\
{[39.0]}\end{array}$ \\
\hline
\end{tabular}

importance of using a more flexible basis set, if the approximate wave functions are not enforced to satisfy virial theorem. It appears that the dominating effect is exerted by the $\pi$-electron system. The overwhelming contributions to aromaticity are provided by the $\Delta V_{\text {ne }}^{\sigma}$ and $\Delta V_{\text {ne }}^{\pi}$ terms, which are as large as -3055.0 [-3259.8] and -289.7 [-304.1] $\mathrm{kcal} / \mathrm{mol}$, respectively. Further, the kinetic energy of the $\pi$-electrons in benzene is more favorable by $-122.1[-128.0] \mathrm{kcal} / \mathrm{mol}$. These results are intuitively appealing, because they are in harmony with our notion that the molecular stability is a consequence of the prevailing attractive interactions, i.e. by the increased nuclearelectron attractions.

In conclusion, summarizing results obtained by eqs $11-13$ it is fair to say that the extrinsic aromatic stabilization of benzene is predominantly a consequence of the more favorable $\pi$-electron system.

Findings derived by homostructural reaction 11 are in direct contradiction with results obtained by analysis of aromaticity based on eq 1 involving linear polyenes as reference nonaromatic compounds. ${ }^{40}$ According to previous analysis aromaticity 
of $\mathbf{B}$ was a result of the more favorable $\sigma$-framework and the most important contribution to its stabilization was an advantageous decrease in $V_{\mathrm{ee}}^{\sigma}$ and $V_{\mathrm{nn}}^{\sigma}$ repulsions according to SHR and EQP partitioning recipes. We conclude that eq 11 offers a better definition of aromaticity of $\mathbf{B}$ than eq 1, since it includes homostructural molecules left and right thus being more balanced. These results corroborate arguments put forward by Schleyer et al. ${ }^{49,50}$ The failure of eq 1 can be traced down to the fact that it is not homostructural, since a ring compound is compared to a linear polyene. Their intramolecular interactions widely differ, because polyene cannot successfully model interactions between non-nearest neighbor atoms and bonds distributed along the cyclic perimeter. Moreover, eq 11 has balanced 1,3-interactions, which are not conserved in eq 1 . Concomitantly, the aromatic stabilization of $\mathbf{B} \Delta E(\text { ease })_{\mathbf{B}}^{\prime}$ of $-38.3 \mathrm{kcal} / \mathrm{mol}$ should be considered a better estimate of the aromaticity of benzene than $\Delta E$ (ease $)_{\mathbf{B}}$ of approximately -22 to $-24 \mathrm{kcal} / \mathrm{mol}$, obtained by linear polyenes via eq 1.40

Once the aromaticity of $\mathbf{B} \Delta E$ (ease) $)_{\mathbf{B}}^{\prime}$ is determined, its change induced by fluorination can be straightforwardly estimated according to reactions 14-19:

$$
\begin{gathered}
\mathbf{1}+\mathbf{2 0}=\mathbf{B}+\mathbf{2 2}+\Delta E(\mathbf{1})^{\prime} \\
\mathbf{2}+2(\mathbf{2 0})=\mathbf{B}+2(\mathbf{2 2})+\Delta E(\mathbf{2})^{\prime} \\
\mathbf{3}+3(\mathbf{2 0})=\mathbf{B}+3(\mathbf{2 2})+\Delta E(\mathbf{3})^{\prime} \\
\mathbf{4}+4(\mathbf{2 0})=\mathbf{B}+4(\mathbf{2 2})+\Delta E(\mathbf{4})^{\prime} \\
\mathbf{5}+5(\mathbf{2 0})=\mathbf{B}+5(\mathbf{2 2})+\Delta E(\mathbf{5})^{\prime} \\
\mathbf{6}+6(\mathbf{2 0})=\mathbf{B}+6(\mathbf{2 2})+\Delta E(\mathbf{6})^{\prime}
\end{gathered}
$$

where $\mathbf{2 2}$ is the monofluoro derivative of $\mathbf{2 0}$ substituted at position 2 (Figure 2). It should be noticed that $\Delta E(\mathbf{n})^{\prime}$ (where $\mathbf{n}=\mathbf{1}-\mathbf{6})$ gives the change in stabilization caused by successive fluorination at the nearest next position. It is determined relative to the aromatic stabilization $\Delta E$ (ease) $)_{\mathbf{B}}^{\prime}$ of benzene. This is easily checked by considering for example $\mathbf{1}$ and the corresponding eq 14, which should be compared with fluorobenzene 1 related to cyclic polyenes only (i.e. without benzene) according to eq 20:

$$
\mathbf{1}+3(\mathbf{1 9})=\mathbf{2 2}+2(\mathbf{2 0})+\mathbf{2 1}+\Delta E(\mathbf{1})^{\prime \prime}
$$

It should be noted that prime and double prime in eqs 19 and 20 have nothing to do with the symmetry notation $a^{\prime}$ and $a^{\prime \prime}$. A combination of eqs 11,14 , and 20 yields

$$
\Delta E(\mathbf{1})^{\prime}=\Delta E(\mathbf{1})^{\prime \prime}-\Delta E(\text { ease })_{\mathbf{B}}^{\prime}
$$

Analogous relations hold for polysubstituted benzenes. In other words, two systems of reactions, one defined by eqs 14-19 and the other by eq 22, where $\mathbf{n}=\mathbf{1 - 6}$, are equivalent, the difference being the stabilization energy of benzene $\Delta E$ (ease) $)_{\mathbf{B}}^{\prime}$ taken as a reference value,

$$
\Delta E(\mathbf{n})^{\prime}=\Delta E(\mathbf{n})^{\prime \prime}-\Delta E(\text { ease })_{\mathbf{B}}^{\prime}
$$

which is useful to keep in mind.

The component energy analysis of $\Delta E(\mathbf{n})^{\prime}$ values is given in Table 2. Perusal of the data shows that $\Delta E(\mathbf{n})^{\prime}$ values are 0.6 [0.8], 6.4 [6.3], 12.6 [12.1], 20.2 [19.3], 28.3 [26.9], and 41.4 [39.0] $\mathrm{kcal} / \mathrm{mol}$ for $\mathbf{n}=\mathbf{1}-\mathbf{6}$ correspondingly, as obtained by the HF/cc-pVDZ [HF/cc-pVTZ] model. It appears that fluorobenzenes are less stable than $\mathbf{B}$ and that decrease in stability is proportional to the number of $\mathrm{F}$ atoms. Recalling that the aromatic stabilization of $\mathbf{B}$ is $-38.3[-37.9] \mathrm{kcal} / \mathrm{mol}$, it appears that all $\Delta E(\mathbf{n})^{\prime \prime}$ values are negative, but one for $\mathbf{n}=\mathbf{6}$. Hexafluorobenzene is slightly destabilized system (by 3.1 [1.1] $\mathrm{kcal} / \mathrm{mol}$ ), although even in this case 6 still has some intrinsic aromatic stabilization, which is overshadowed by the F,F repulsions, as it will turn out later. Further, decreased stability of fluorinated benzenes relative to the parent benzene is a result of the destabilized $\sigma$-framework according to SHR and EQP schemes, whereas the standard $\pi$-partitioning SPI indicates the opposite as usual, implying that the $\pi$-framework is the origin of the destabilization effect upon fluorination. It is of interest to examine particular energy terms within the SHR scheme in some more detail. Since $\mathbf{1}$ exhibits a singular behavior, we shall postpone its discussion to a later stage. In fluorobenzenes 2-6 the stabilizing factors are nuclear-electron terms $\Delta V_{\text {ne }}^{\sigma}$ and $\Delta$ $V_{\text {ne }}^{\pi}$ just like in the parent $\mathbf{B}$. An additional stabilizing energy component is the kinetic energy of $\sigma$-electrons. Its influence increases with the number of $\mathrm{F}$ atoms, meaning that the $\Delta T^{\sigma}$ increases in its absolute value. In contrast, the kinetic energy of $\pi$-electrons is a destabilizing factor, since its numerical value increases with the number of $\mathrm{F}$ atoms. The sum $\Delta T^{\sigma}+\Delta T^{\pi}$ becomes more negative with the increased number of $F$ atoms and with the improved flexibility of the basis set as exemplified by the HF/cc-pVTZ results. We shall concentrate next on the $\Delta V_{\text {ee }}$ and $\Delta V_{\mathrm{nn}}$ terms, which depend on the partitioning schemes. Let us consider the SHR partitioning, since the EQP yields the same general conclusions. It turns out that $\Delta V_{\mathrm{ee}}^{\sigma}$ and $\Delta V_{\mathrm{nn}}^{\sigma}$ terms are strongly unfavorable like in the parent $\mathbf{B}$. The same holds for the $\Delta V_{\mathrm{ee}}^{\pi}$ and $\Delta V_{\mathrm{nn}}^{\pi}$ terms, 1,2-difluorobenzene $\mathbf{2}$ being a notable exception. The influence of the repulsive terms increases with the number of $\mathrm{F}$ atoms. This is understandable in view of a larger number of fluorines and their pairwise repulsions. It is also obvious that the fluorine $\sigma$-lone pairs at vicinal positions exert a stronger repulsion than the $\pi$-lone pairs. The same holds for the nuclear $\Delta V_{\mathrm{nn}}^{\sigma}$ term compared to $\Delta V_{\mathrm{nn}}^{\pi}$ repulsion. For example, in going from 4 to 5 the $\sigma$ - and $\pi$-electron repulsions are increased by $\Delta \Delta V_{\mathrm{ee}}^{\sigma}=16754.4$ [16774.9] $\mathrm{kcal} / \mathrm{mol}$ and $\Delta \Delta V_{\mathrm{ee}}^{\tau}=2804.9$ [2819.1] $\mathrm{kcal} / \mathrm{mol}$, respectively. Similarly, the nuclear repulsion terms are increased by $\Delta \Delta V_{\mathrm{nn}}^{\sigma}=17372.8$ [17399.4] and $\Delta \Delta V_{\mathrm{nn}}^{\pi}=2632.4$ [2605.9] (in $\mathrm{kcal} / \mathrm{mol}$ ), where the HF/cc-pVTZ results are given within the square brackets.

Let us come back to the case of fluorobenzene 1 now. The energy components are easily understood, if eq 21 is invoked. The latter shows that $\Delta E(\mathbf{1})^{\prime}$ is a difference between two large numbers. It appears that for example $\Delta T^{\sigma}(\mathbf{1})^{\prime \prime}$ is by $1.3 \mathrm{kcal} /$ mol larger than $\Delta T^{\sigma}(\mathbf{B})$, whereas $\Delta T^{\pi}(\mathbf{1})^{\prime \prime}$ is by $3.0 \mathrm{kcal} / \mathrm{mol}$ lower than the corresponding value in benzene $\Delta T^{\pi}(\mathbf{B})^{\prime}$. This explains their unusually low values and opposite signs compared to all other di- and polysubstituted fluorobenzenes. Similarly, $\Delta V_{\text {ne }}^{\sigma}(\mathbf{1})^{\prime \prime}-\Delta V_{\text {ne }}^{\sigma}(\mathbf{B})^{\prime}$ is positive, yielding $523.9 \mathrm{kcal} / \mathrm{mol}$, which differs in sign compared to other fluorobenzenes too. The reason behind this is that $\Delta V_{\mathrm{ne}}^{\sigma}(\mathbf{1})^{\prime \prime}$ is in fact a negative quantity $(-2531.1 \mathrm{kcal} / \mathrm{mol})$, but $\Delta V_{\mathrm{ne}}^{\sigma}(\mathbf{B})^{\prime}$ in benzene assumes an even lower value $(-3055.0 \mathrm{kcal} / \mathrm{mol})$. It follows that peculiar energy components $\Delta E(\mathbf{1})^{\prime}$ are a consequence of the fact that they are measured against their counterparts in benzene. In polysubstituted fluorobenzenes the influence of the reference benzene terms plays a less important role and a simple and regular pattern of energy changes occurs.

A brief discussion of the $\Delta E(\mathbf{n})^{\prime \prime}$ energies obtained by eq 22 is illuminating in this respect. Their values are easily deduced 


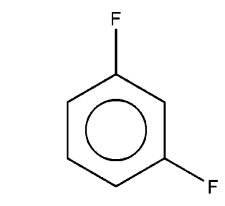

23

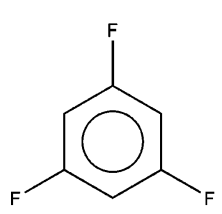

26

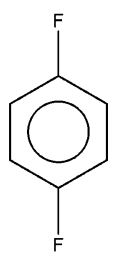

24

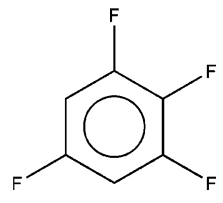

27

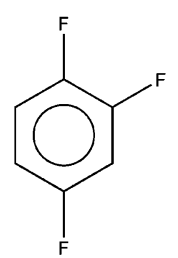

25

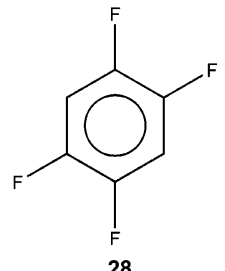

28
Figure 3. Schematic representation of fluorinated benzenes necessary to establish the additivity rule for the substituent effect.

from $\Delta E(\mathbf{n})^{\prime}$ and $\Delta E$ (ease $)_{\mathbf{B}}{ }^{\prime}$ energies given in Table 2. The same holds for their energy components. Both cc-pVDZ and cc-pVTZ basis set HF model calculations show that the stabilizing $\Delta E(\mathbf{n})^{\prime \prime}$ energies for $\mathbf{n}=\mathbf{1}-\mathbf{5}$ are a consequence of the $\pi$-electron framework. The $\sigma$-framework is destabilized by the fluorine substitution(s), which is plausible and intuitively clear, since the strong perturbation takes place in the $\sigma$-plane, while the $\pi$-network is perturbed to a lesser extent. In the hexafluorobenzene $\mathbf{6}$ the $\sigma$-framework prevails and $\Delta E(\mathbf{n})^{\prime \prime}$ becomes slightly positive, i.e. destabilizing.

To conclude this section, let us just mention that the use of nonplanar cyclohexadiene and cyclohexene compounds in homostructural reactions makes the $\sigma / \pi$ separation very difficult. The unambiguous distinction between the $\sigma$ - and $\pi$-orbitals is not possible. The canonical HF MOs tend to be delocalized over the entire molecules leading to a strong mixing of localized or semilocalized $\pi$ - and $\sigma$-orbitals. Although their mixing does not necessarily imply strong $\sigma / \pi$ interactions, it renders canonical $\mathrm{HF}$ orbitals useless in providing unique and balanced decomposition of the electron density into the $\sigma$ - and $\pi$-components, not to mention additional ambiguities given by partitioning of the $V_{\mathrm{nn}}$ term.

3.3. The Effect of Fluorination on Aromaticity: Isostructural Reactions. It would be useful to delineate the throughspace interaction of the fluorine atoms from the changes in aromatic stabilization of the benzene moiety. For this purpose we shall consider ortho, meta, and para disubstituted fluorobenzenes denoted by $\mathbf{2 , 2 3}$, and $\mathbf{2 4}$ (Figures 1 and 3), respectively. We shall show that the substituent effects in fluorobenzenes follow an interesting additivity rule in terms of two-body (two $\mathrm{F}$ atoms) interactions. The increments describing ortho, meta, and para effects mediated by the aromatic fragment and by the direct through-space interactions are given by isostructural reactions $23-25$ :

$$
\begin{gathered}
\mathbf{2}+\mathbf{B}=2(\mathbf{1})+I_{o}(\mathrm{~F}, \mathrm{~F})^{\prime \prime \prime} \\
\mathbf{2 3}+\mathbf{B}=2(\mathbf{1})+I_{m}(\mathrm{~F}, \mathrm{~F})^{\prime \prime \prime} \\
\mathbf{2 4}+\mathbf{B}=2(\mathbf{1})+I_{p}(\mathrm{~F}, \mathrm{~F})^{\prime \prime \prime}
\end{gathered}
$$

where $o, m$, and $p$ have the obvious meanings. The term isostructural reaction implies that the spatial structures of educts and products are virtually the same apart from some tiny details. In order to extend the family of polyfluorinated benzenes $3-\mathbf{6}$, some additional members 25-28 (Figure 3) are examined too. The corresponding isostructural reactions read

$$
\begin{aligned}
\mathbf{3}+2 \mathbf{B} & =3(\mathbf{1})+\Delta E(\mathbf{3})^{\prime \prime \prime} \\
\mathbf{2 5}+2 \mathbf{B} & =3(\mathbf{1})+\Delta E(\mathbf{2 5})^{\prime \prime \prime} \\
\mathbf{2 6}+2 \mathbf{B} & =3(\mathbf{1})+\Delta E(\mathbf{2 6})^{\prime \prime \prime} \\
\mathbf{4}+3 \mathbf{B} & =4(\mathbf{1})+\Delta E(\mathbf{4})^{\prime \prime \prime} \\
\mathbf{2 7}+3 \mathbf{B} & =4(\mathbf{1})+\Delta E(\mathbf{2 7})^{\prime \prime \prime} \\
\mathbf{2 8}+3 \mathbf{B} & =4(\mathbf{1})+\Delta E(\mathbf{2 8})^{\prime \prime \prime} \\
\mathbf{5}+4 \mathbf{B} & =5(\mathbf{1})+\Delta E(\mathbf{5})^{\prime \prime \prime} \\
\mathbf{6}+5 \mathbf{B} & =6(\mathbf{1})+\Delta E(\mathbf{6})^{\prime \prime \prime}
\end{aligned}
$$

It will become obvious that the substituent effects measured against the monofluorobenzene 1 and defined by eqs 26-33 are almost accurately additive according to the formula

$$
\Delta E(\mathbf{n})^{\prime \prime \prime}=\sum_{\alpha} I_{\alpha}(\mathrm{F}, \mathrm{F})^{\prime \prime \prime}
$$

where summation over $\alpha$ is extended over all possible increments $(\alpha=o, m, p)$ in a polysubstituted benzene for $\mathbf{n}>\mathbf{2}$. In other words, there are three types of interactions between two substituted fluorines depending on their relative ortho, meta, and para positions and the total substituent effect is a sum of all possible pair-interaction energies given by increments $I_{o}(\mathrm{~F}$, $\mathrm{F})^{\prime \prime \prime}, I_{m}(\mathrm{~F}, \mathrm{~F})^{\prime \prime \prime}$, and $I_{p}(\mathrm{~F}, \mathrm{~F})^{\prime \prime \prime}$. Additional $\mathrm{F}$ atoms, if present, do not affect and change these elementary pair-interactions. It should be noted that the increments include the $\sigma$-inductive, $\pi$-electron back-bonding and through-space nonbonding effects. The former two types of interactions lead to a possible change in aromaticity. Unraveling all these effects is a formidable task. It is fortunate, however, that an almost accurate additivity of the fluorine substituent effects provides important clues how to achieve this goal. For this purpose we need $I_{o}(\mathrm{~F}, \mathrm{~F})^{\prime \prime \prime}, I_{m}(\mathrm{~F}$, $\mathrm{F})^{\prime \prime \prime}$, and $I_{p}(\mathrm{~F}, \mathrm{~F})^{\prime \prime \prime}$ increments, which are 5.1, 0.5, and $1.6 \mathrm{kcal} /$ mol, respectively, as obtained by the HF/cc-pVDZ model. Results of the analysis are presented in Table 3. It appears that the additivity works amazingly well. This is evidenced by the following data: 10.7 (10.7), 7.1 (7.2), 1.7 (1.5), 17.7 (17.9), 13.2 (13.3), 14.2 (14.4), 25.2 (25.6), and 37.6 (37.9) (in kcal/ $\mathrm{mol}$ ), where additivity values are given in parentheses, for $\mathbf{3}$, $25,26,4,27,28,5$, and 6 , respectively. The average absolute deviation of the additivity values from the HF results is 0.2 $\mathrm{kcal} / \mathrm{mol}$, which is very small indeed.

This has several important consequences. First, the changes in stabilization energies for molecules $\mathbf{2 - 6}$ are close to those obtained earlier by eqs $14-19$ as easily verified by the data in Table 2. This lends strong support and credence to the results obtained by homostructural reactions $14-19$, which employ model compounds enforced to be planar. Moreover, the energy component analysis provides comparable values (viz., Tables 2 and 3). In particular, it follows that the changes in stability induced by fluorination $\Delta E(\mathbf{n})^{\prime \prime \prime}$ are governed by the $\sigma$-framework contributions $\left(\Delta E^{\sigma}\right)^{\prime \prime \prime}$ (Table 3 ). More specifically, a decrease in stability is caused by the repulsive $\left(\Delta V_{\mathrm{ee}}^{\sigma}\right)^{\prime \prime \prime},(\Delta$ $\left.V_{\mathrm{ee}}^{\tau}\right)^{\prime \prime \prime},\left(\Delta V_{\mathrm{nn}}^{\sigma}\right)^{\prime \prime \prime}$, and $\left(\Delta V_{\mathrm{nn}}^{\pi}\right)^{\prime \prime \prime}$ terms. In contrast, the $\left(\Delta V_{\mathrm{ne}}^{\sigma}\right)^{\prime \prime \prime}$ and $\left(\Delta V_{\mathrm{ne}}^{\pi}\right)^{\prime \prime \prime}$ terms are strongly stabilizing as in the parent $\mathbf{B}$. The kinetic energy of the $\sigma$-electrons $\left(\Delta T^{\sigma}\right)^{\prime \prime \prime}$ is a strong stabilizing factor in polysubstituted fluorobenzenes, but it is counterbalanced by the destabilizing $\left(\Delta T^{\pi}\right)^{\prime \prime \prime}$ effect. The total 
TABLE 3: Values of $\sigma$ and $\pi$ Contributions to the Kinetic and Potential Energy Parts of the Changes in Total HF Energy $\Delta E_{\mathrm{HF}}^{\text {tot }}$ for Isostructural Reactions 23-33, Obtained at the HF/cc-pVDZ Level of Theory (in $\mathrm{kcal} / \mathrm{mol}$ )

\begin{tabular}{|c|c|c|c|c|c|c|c|c|c|c|c|}
\hline compd/(eq) & $\Delta T^{\sigma}$ & $\Delta T^{\pi}$ & $\Delta V_{\mathrm{ne}}^{\sigma}$ & $\Delta V_{\mathrm{ne}}^{\pi}$ & $\Delta V_{\mathrm{ee}}^{\sigma}$ & $\Delta V_{\mathrm{ee}}^{\pi}$ & $\Delta V_{\mathrm{nn}}^{\sigma}$ & $\Delta V_{\mathrm{nn}}^{\pi}$ & $\Delta E^{\sigma}$ & $\Delta E^{\pi}$ & $\Delta E^{\mathrm{to}}$ \\
\hline $2 /(23)$ & -30.2 & 29.5 & -11507.3 & -4002.2 & & & & & & & \\
\hline SHR & & & & & 6355.7 & 1351.3 & 6613.7 & 1194.5 & 1431.9 & -1426.8 & 5.1 \\
\hline EQP & & & & & 5733.7 & 1973.3 & 6613.7 & 1194.5 & 810.0 & -804.8 & 5.1 \\
\hline SPI & & & & & 4261.8 & 3445.3 & 7808.2 & & 532.5 & -527.4 & 5.1 \\
\hline $23 /(24)$ & -10.3 & 10.0 & -6961.8 & -2353.2 & & & & & & & \\
\hline SHR & & & & & 3654.6 & 940.2 & 3930.1 & 790.4 & 633.2 & -632.7 & 0.5 \\
\hline EQP & & & & & 868.5 & 3428.0 & 3930.1 & 790.4 & 406.6 & -406.1 & 0.5 \\
\hline SPI & & & & & 2559.5 & 2035.3 & 4720.5 & & 328.5 & -327.9 & 0.5 \\
\hline $\mathbf{2 4} /(25)$ & -23.6 & 23.3 & -5613.8 & -2070.7 & & & & & & & \\
\hline SHR & & & & & 2944.4 & 866.7 & 3185.8 & 689.5 & 492.8 & -491.2 & 1.6 \\
\hline EQP & & & & & 2796.2 & 1014.9 & 3185.8 & 689.5 & 344.6 & -343.0 & 1.6 \\
\hline SPI & & & & & 2047.3 & 1763.8 & 3875.2 & & 285.1 & -283.6 & 1.6 \\
\hline $3 /(26)$ & -51.0 & 50.1 & -29919.3 & -10346.8 & & & & & & & \\
\hline SHR & & & & & 16392.2 & 3588.1 & 17120.8 & 3176.6 & 3542.6 & -3531.9 & 10.7 \\
\hline EQP & & & & & 14871.5 & 5108.7 & 17120.8 & 3176.6 & 2022.0 & -2011.3 & 10.7 \\
\hline SPI & & & & & 11063.3 & 8916.9 & 20297.4 & & 1390.4 & -1379.7 & 10.7 \\
\hline $25 /(27)$ & -43.3 & 42.2 & -24018.1 & -8406.6 & & & & & & & \\
\hline SHR & & & & & 12985.7 & 3087.4 & 13702.0 & 2657.6 & 2626.4 & -2619.2 & 7.1 \\
\hline EQP & & & & & 11927.0 & 4146.1 & 13702.0 & 2657.6 & 1567.7 & -1560.6 & 7.1 \\
\hline SPI & & & & & 8844.8 & 7228.3 & 16359.6 & & 1143.1 & -1135.9 & 7.1 \\
\hline $26 /(28)$ & 29.6 & -29.1 & -20923.3 & 7078.0 & & & & & & & \\
\hline SHR & & & & & 11065.1 & 2750.0 & 11832.9 & 2354.4 & 2004.4 & -2002.7 & 1.7 \\
\hline EQP & & & & & 3509.6 & 8762.1 & 11832.9 & 2354.4 & 1244.8 & -1243.1 & 1.7 \\
\hline SPI & & & & & 7693.3 & 6121.9 & 14187.3 & & 986.9 & -985.2 & 1.7 \\
\hline $4 /(29)$ & -94.8 & 93.1 & -53841.6 & -18726.0 & & & & & & & \\
\hline SHR & & & & & 29422.1 & 6575.5 & 30771.3 & 5818.0 & 6257.1 & -6239.4 & 17.7 \\
\hline EQP & & & & & 26755.4 & 9242.2 & 30771.3 & 5818.0 & 3590.4 & -3572.7 & 17.7 \\
\hline SPI & & & & & 19875.0 & 16122.7 & 36589.3 & & 2527.9 & -2510.2 & 17.7 \\
\hline $27 /(30)$ & -54.3 & 53.2 & -49379.4 & -17106.1 & & & & & & & \\
\hline SHR & & & & & 26788.1 & 6151.7 & 28158.4 & 5401.7 & 5512.8 & -5499.5 & 13.2 \\
\hline EQP & & & & & 24489.8 & 8449.9 & 28158.4 & 5401.7 & 3214.5 & -3201.3 & 13.2 \\
\hline SPI & & & & & 18202.1 & 14737.6 & 33560.2 & & 2328.5 & -2315.3 & 13.2 \\
\hline $\mathbf{2 8} /(31)$ & -87.7 & 85.9 & -47845.8 & -16768.4 & & & & & & & \\
\hline SHR & & & & & 25974.4 & 6059.9 & 27313.9 & 5281.9 & 5354.8 & -5340.6 & 14.2 \\
\hline EQP & & & & & 23763.9 & 8270.4 & 27313.9 & 5281.9 & 3144.3 & -3130.1 & 14.2 \\
\hline SPI & & & & & 17617.3 & 14417.0 & 32595.8 & & 2279.6 & -2265.5 & 14.2 \\
\hline $5 /(32)$ & -129.6 & 127.2 & -84611.5 & -29439.6 & & & & & & & \\
\hline SHR & & & & & 46187.4 & 10362.6 & 48319.1 & 9209.5 & 9765.5 & -9740.3 & 25.2 \\
\hline EQP & & & & & 42016.0 & 14543.0 & 48319.1 & 9209.5 & 5594.1 & -5568.9 & 25.2 \\
\hline SPI & & & & & 31202.8 & 25347.2 & 57528.6 & & 3990.4 & -3965.2 & 25.2 \\
\hline $6 /(33)$ & -195.8 & 192.5 & -126743.7 & -44117.1 & & & & & & & \\
\hline SHR & & & & & 69358.8 & 15369.4 & 72396.9 & 13776.6 & 14816.2 & -14778.5 & 37.6 \\
\hline EQP & & & & & 24489.8 & 8449.9 & 72396.9 & 13776.6 & 3214.5 & -3201.3 & 37.6 \\
\hline SPI & & & & & 46742.8 & 37985.3 & 86173.5 & & 5976.9 & -5939.2 & 37.6 \\
\hline
\end{tabular}

SCHEME 1

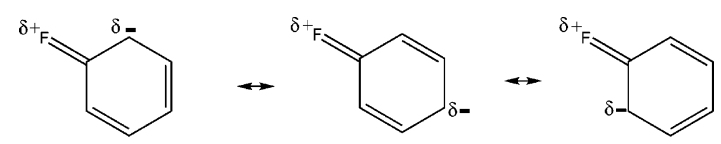

kinetic energy contribution is practically nil, $\left(\Delta T^{\sigma}\right)^{\prime \prime \prime}+\left(\Delta T^{\pi}\right)$ '" $\cong 0$. Perhaps the most important outcome of the isostructural reactions analysis 23-33 is separation of the direct interaction of fluorines from the aromatic effect. Consider the increments $I_{o}(\mathrm{~F}, \mathrm{~F})^{\prime \prime \prime}, I_{m}(\mathrm{~F}, \mathrm{~F})^{\prime \prime \prime}$, and $I_{p}(\mathrm{~F}, \mathrm{~F})^{\prime \prime \prime}$. It is well-known that the ortho and para positions behave similarly as far as the electronic effects are concerned, which is reflected e.g. in the electrophilic substitution reactions. This is rather nicely illustrated by the $\pi$-back-bonding effect evidenced by the resonance structures (Scheme 1).

There is obviously a drift of some of the $\pi$-electron density from fluorine to the ortho and para positions. The meta positions are different in a sense that they remain inactivated by the $\pi$-electron resonance effect. Hence, $I_{m}(\mathrm{~F}, \mathrm{~F})^{\prime \prime \prime}=0.5 \mathrm{kcal} / \mathrm{mol}$ is a consequence of the $\sigma$-inductive effect, if it is tacitly assumed that the through-space repulsion can be neglected. Further, $I_{p^{-}}$ $(\mathrm{F}, \mathrm{F})^{\prime \prime \prime}=1.6 \mathrm{kcal} / \mathrm{mol}$ indicates that the $\pi$-resonance effect producing negative charge at the para position contributes 1.1 $\mathrm{kcal} / \mathrm{mol}$ to destabilization, since this is obviously an unfavorable charge distribution for the para placed $\mathrm{F}$ atoms. It is supposed here that the inductive effect is the same as for the meta position. It can be concluded that $I_{p}(\mathrm{~F}, \mathrm{~F})^{\prime \prime \prime}$ represents a decrease in aromaticity relative to two monofluorobenzenes according to eq 25 through the inductive and $\pi$-resonance mechanisms. Assuming that practically the same holds for the ortho position, one can ascribe an amount of $3.5 \mathrm{kcal} / \mathrm{mol}$ to the effective repulsion of the two vicinally placed $\mathrm{F}$ atoms as a consequence of the Coulomb interaction between their lone pairs and nuclei. These repulsions overwhelm the attraction between the electron 
density of one $\mathrm{F}$ atom and the positive nuclear charge of the other. They are reflected in the corresponding $\left(\Delta V^{\sigma}\right)^{\prime \prime \prime}$ and $\left(\Delta V^{\pi}\right)^{\prime \prime \prime}$ repulsion terms (Table 3 ). In spite of the fact that this description is based on a simplified picture, it is useful in rationalizing the results. It is of interest to analyze the trend of changes of various energy terms along the series $\mathbf{2 , 2 3}$, and $\mathbf{2 4}$. We shall start with the ortho derivative and subsequently move one fluorine to the meta and para positions. In other words, 2 is taken as a reference and the changes taking place in $\mathbf{2 3}$ are given as follows: $\Delta_{o} T(\mathbf{2 3})=0.4, \Delta_{o} V_{\mathrm{ne}}^{\sigma}(\mathbf{2 3})=4545.5, \Delta_{o}$ $V_{\mathrm{ne}}^{\pi}(\mathbf{2 3})=1649.0, \Delta_{o} V_{\mathrm{ee}}^{\sigma}(\mathbf{2 3})=-2701.1, \Delta_{o} V_{\mathrm{ee}}^{\pi}(\mathbf{2 3})=-411.1$, $\Delta_{o} V_{\mathrm{nn}}^{\sigma}(\mathbf{2 3})=-2683.6$, and $\Delta_{o} V_{\mathrm{nn}}^{\pi}(\mathbf{2 3})=-404.1$, in $\mathrm{kcal} / \mathrm{mol}$, where index $o$ denotes the ortho substituted reference molecule 2. In other words, the nuclear-electron attraction is considerably decreased in meta substituted difluorobenzene. This is obvious, since the electron density of the first fluorine in $\mathbf{2}$ is strongly attracted by the nucleus of the second ortho positioned fluorine and vice versa. This interaction is considerably weaker in the meta derivative 23. At the same time there is a substantial decrease in the electron and internuclear repulsions in $\mathbf{2 3}$. It is a result of the increased average distance between the electron densities and nuclear charges of F atoms. Since the latter effect prevails, the total sum of potential energy terms is stabilizing, given $\Delta_{o} V(\mathbf{2 3})=\Delta_{o} V_{\mathrm{ne}}+\Delta_{o} V_{\mathrm{ee}}+\Delta_{o} V_{\mathrm{nn}}=(6194.5-3112.2-$ $3087.7)=-5.4 \mathrm{kcal} / \mathrm{mol}$. This stabilization should be diminished by $0.4 \mathrm{kcal} / \mathrm{mol}$ due to increase in the kinetic energy of electrons. Analogously, the corresponding changes for parasubstituted pair of the $\mathrm{F}$ atoms read $\Delta_{o} T(\mathbf{2 4})=0.4, \Delta_{o} V_{\mathrm{ne}}^{\sigma}(\mathbf{2 4})$ $=5893.5, \Delta_{o} V_{\mathrm{ne}}^{\pi}(\mathbf{2 4})=1931.5, \Delta_{o} V_{\mathrm{ee}}^{\sigma}(\mathbf{2 4})=-3411.3, \Delta_{o}$ $V_{\mathrm{ee}}^{\pi}(\mathbf{2 4})=-464.6, \Delta_{o} V_{\mathrm{nn}}^{\sigma}(\mathbf{2 4})=-3427.9$, and $\Delta_{o} V_{\mathrm{nn}}^{\pi}(\mathbf{2 4})=$ $-505.0 \mathrm{kcal} / \mathrm{mol}$. The changes in particular terms are much more pronounced, but the pattern is the same as expected. The change in the total energy is (in $\mathrm{kcal} / \mathrm{mol}) \Delta_{o} T(\mathbf{2 4})+\Delta_{o} V(\mathbf{2 4})=0.4-$ $3.8=-3.4$. It follows that the ortho, meta, and para effects are results of dramatic changes in particular modes of the intramolecular interactions, although their final sums are rather small. It is amazing that subtle differences in stability of isomers are the result of a delicate interplay of the very strong attractive and repulsive forces between the electron and nuclei.

In view of the additivity of the pairwise F,F interactions, one can generalize these conclusions to polysubstituted benzenes. It is reasonable to assume that the vicinal repulsions of fluorines are additive, which should be subtracted from the $\Delta E(\mathbf{n})^{\prime \prime \prime}$ energies. In this way one can obtain the aromaticity defect $\Delta E(\mathbf{A D})^{\prime \prime \prime}$, which for $2,23,24,3,25,26,4,27,28,5$, and 6 assumes values of $1.6,0.5,1.6,3.7,0.2,1.5,7.2,6.3,7.4,11.2$, and $16.6 \mathrm{kcal} / \mathrm{mol}$, respectively. Namely, these numbers yield additional destabilization beyond the effective repulsion of the vicinal F,F pairs(s), which is ascribed to a decreased aromatic stabilization of the multiply fluorinated benzene. In a subset of compounds $\mathbf{3}, \mathbf{4}, \mathbf{5}$, and $\mathbf{6}$, where each additional $\mathrm{F}$ atom is placed successively to the first available vicinal position, the aromaticity defect in the $\mathbf{n}$-tuple substituted fluorobenzene is practically additive being by $3.7 \mathrm{kcal} / \mathrm{mol}$ larger compared to the preceding $\mathbf{n}-1$ fluorobenzene. It follows as a corollary that both the aromaticity defect and through-space fluorine repulsions decrease stability of the fluorobenzenes. Since fluorobenzene $\mathbf{1}$ is destabilized relative to $\mathbf{B}$ by $\Delta E(\mathbf{1})^{\prime}=0.6$ $\mathrm{kcal} / \mathrm{mol}$, we arrive at the following aromaticity defects estimated by taking benzene as a reference: $2.8,5.5,9.8$, and $20.5 \mathrm{kcal} / \mathrm{mol}$ for $\mathbf{2}, \mathbf{3}, \mathbf{4}, \mathbf{5}$, and $\mathbf{6}$, respectively. It should be noticed that the aromaticity defect $\triangle E(\mathbf{A D})^{\prime \prime \prime}$ is doubled by each subsequent vicinal fluorination. Taking into account that $\Delta E(\mathbf{6})-$ "' is $37.6 \mathrm{kcal} / \mathrm{mol}$ (Table 3 ), one arrives at the conclusion that $\mathbf{6}$ is less stable than $\mathbf{B}$ by $41.2 \mathrm{kcal} / \mathrm{mol}$. This estimate is obtained by taking into account that stability of $\mathbf{6}$ is gauged against six monofluorobenzenes 1 (eq 33). Namely, each monofluorobenzene is by $0.6 \mathrm{kcal} / \mathrm{mol}$ less stable than benzene B. Since the aromatic stabilization of $\mathbf{B}$ is $-38.3 \mathrm{kcal} / \mathrm{mol}$ (eq 11), it follows paradoxically enough that $\mathbf{6}$ is formally a nonaromatic compound as far as its total stability is concerned and yet it still involves an intrinsic aromatic stabilization of $17.8 \mathrm{kcal} / \mathrm{mol}$. The latter is obtained as a difference between $\Delta E$ (ease $)_{\mathbf{B}}^{\prime}$ of a free benzene $(-38.3 \mathrm{kcal} / \mathrm{mol})$ and the aromaticity defect $\Delta E(\mathbf{A D})$ "' of $20.5 \mathrm{kcal} / \mathrm{mol}$ in $\mathbf{6}$.

To conclude, the system of isostructural reactions 23-33 provides a simple and intellectually appealing insight into the interplay between aromaticity and pairwise interactions of fluorines in fluorobenzenes. It should be strongly pointed out, however, that eqs 23-33 cannot say anything about aromaticity of benzene $\mathbf{B}$ and fluorobenzene $\mathbf{1}$ itself. For this purpose the model homostructural eqs 11 and 14 have to be invoked.

3.4. The Influence of the Electron Correlation and Zero Point Vibrational Energies. It is generally accepted that the electron correlation does not affect the homodesmotic reaction energies, since there are the same number and type of the electron pairs left and right. A better argument is given by the additivity of the electron correlation energies for molecules well described by the Lewis structures. We have shown that the total electron correlation energy of the closed shell molecules in their ground state could be satisfactorily described by homogeneous multilinear function of the number of polarized neutral atoms in their canonical hybridization states. ${ }^{52}$ Performance of the additivity formula was excellent as evidenced by the average absolute deviation from the $\mathrm{G} 3$ results $(A A D(\mathrm{G} 3)=1.2 \mathrm{kcal} /$ mol) and the correlation coefficient $R^{2}=0.99998$. The same additivity rule mutatis mutandis holds for the MP2 $2^{53}$ and DFTB3LYP ${ }^{4}$ methodologies. Some nonadditivities were found, however, for planar aromatic molecules, where the nondynamical correlation energy of e.g. benzene is lower than that in the open chain polyene counterparts. ${ }^{55-57}$ This is remedied, however, to some extent by the dynamical correlation energy, which is in aromatic molecules higher than that in the zigzag polyenes. In particular, it is shown that the correlation energy obtained as a sum of the nondynamical and dynamical correlations of planar molecules is close to the MP2 correlation energy, provided they are obtained by the $\mathrm{CASSCF}^{\pi}$ and $\mathrm{CASPT}^{(\pi)+o}$ methods. ${ }^{58}$ The latter includes all valence electrons in the PT2 procedure. Since the single configuration MP2 method gives very similar results as the multiconfigurational $\mathrm{CASSCF}+$ CASPT2 approach even in planar systems, it will be our method of choice here. It enables, namely, that both planar and nonplanar molecules are treated on the same footing.

The zero point vibrational energies (ZPVEs) belong also to the additive molecular properties, as shown by Schulman, Disch, and others. ${ }^{59,60}$ These findings are corroborated by our simple polarized independent atom model, which proved very useful in reproducing ZPVEs of large variety of small and medium size molecules. ${ }^{61}$ In very large systems the additivity formula yields too low values presumably due to anharmonicity effects.

The influence of the correlation energy and ZPVEs, $\triangle$ (CORR) and $\triangle(\mathrm{ZPVE})$, respectively, is illustrated by the results presented in Table 4. Let us consider eqs 11 and 14-19 first. It appears that the vibrational effect can be safely disregarded unless the best possible quantitative result is desired. The correlation energy affects benzene and its fluorinated derivatives to a somewhat larger extent by increasing their stability. The largest effect $(-4.5 \mathrm{kcal} / \mathrm{mol})$ is found in hexafluorobenzene 6 . However, even 
TABLE 4: Various Contributions to the Total Energies of Reactions Defined by Eqs 11, 14-20, and 23-33 (in $\mathrm{kcal} / \mathrm{mol})^{a}$

\begin{tabular}{rrrrr}
\hline eq & $\Delta E(\mathrm{HF})$ & $\Delta(\mathrm{ZPVE})$ & $\Delta(\mathrm{CORR})$ & $\Delta E_{\text {tot }}$ \\
\hline 11 & -38.3 & 0.6 & -3.7 & -41.4 \\
14 & 0.7 & -0.1 & -0.3 & 0.3 \\
15 & 6.4 & -0.2 & -1.0 & 5.2 \\
16 & 12.7 & -0.4 & -1.5 & 10.8 \\
17 & 20.3 & -0.5 & -2.5 & 17.3 \\
18 & 28.4 & -0.7 & -3.3 & 24.4 \\
19 & 41.5 & -0.8 & -4.5 & 36.2 \\
20 & -37.6 & 0.5 & -4.0 & -41.1 \\
23 & 5.1 & 0.0 & -0.5 & 4.6 \\
24 & 0.5 & 0.0 & 0.1 & 0.6 \\
25 & 1.6 & -0.1 & -0.3 & 1.2 \\
26 & 10.7 & 0.0 & -0.8 & 9.9 \\
27 & 7.1 & -0.1 & -0.7 & 6.3 \\
28 & 1.7 & -0.1 & 0.3 & 1.9 \\
29 & 17.7 & 0.0 & -1.6 & 16.1 \\
30 & 13.2 & -0.1 & -0.9 & 12.2 \\
31 & 14.2 & -0.1 & -1.6 & 12.5 \\
32 & 25.2 & -0.1 & -2.0 & 23.1 \\
33 & 37.6 & -0.1 & -3.1 & 34.4
\end{tabular}

${ }^{a} \Delta E(\mathrm{HF})$ and $\Delta(\mathrm{ZPVE}) \mathrm{s}$ are calculated at the HF/cc-pVDZ level of theory; values of ZPVE are scaled with factor $0.9204 .{ }^{62}$ Correlation energies, $\Delta(\mathrm{CORR})$ are given as difference between total energies calculated on MP2(fc)/cc-pVDZ//HF/cc-pVDZ and those obtained by HF/cc-pVDZ model.

in this case it amounts to about $10 \%$ of the HF destabilization energy, $\Delta E(\mathrm{HF})_{6}=41.5 \mathrm{kcal} / \mathrm{mol}$. It is fair to conclude that the $\mathrm{HF}$ energies describe more than $90 \%$ of the change in energy as a rule. Here, molecules with very small $\Delta E(\mathrm{HF})$ values, like e.g. monofluorobenzene (eq 14) are considered as exceptions, since in this case the electron correlation contribution becomes comparable to the change in HF energy. It is very interesting to mention that the $\triangle(\mathrm{ZPVE})$ values for homostructural eqs $14-$ 19 are little affected by imaginary vibrations of the planar 1,3cyclohexadiene $\mathbf{2 0}$ and monofluorocyclohexadiene 22, since their imaginary frequencies are 0.5 and $0.4 \mathrm{kcal} / \mathrm{mol}$, respectively. It implies that their absence in the corresponding ZPVEs is completely canceled, because these molecules occur on different sides of the homostructural equations.

Isostructural eqs 23-33 are better designed reactions than homostructural ones, which is confirmed by the negligible $\Delta$ (ZPVE) values and significantly smaller electron correlation corrections (Table 4). The latter are less than $2 \mathrm{kcal} / \mathrm{mol}$ in absolute values, the penta- and hexafluoro derivatives $\mathbf{5}$ and $\mathbf{6}$ being two notable exceptions.

\section{Concluding Remarks}

The main results can be epitomized as follows:

(1) Aromaticity cannot be satisfactorily defined by using homodesmotic reactions employing the open chain zigzag polyenes. These reactions are not homostructural and give misleading results, since the intramolecular interactions in the educts and products are not well balanced. Therefore, linear polyenes cannot serve as the reference systems for determining aromaticity of cyclic planar molecules. They should be abandoned as inadequate after their intensive use in the last fifty years.

(2) A better definition of the aromaticity of benzene is offered by homostructural reaction involving cyclic systems such as 1,3cyclohexadiene and cyclohexene as reference nonaromatic molecules (viz., eq 11). Moreover, these molecules have to be enforced to assume planar backbone geometries (defined by carbon atoms) in order to enable $\sigma / \pi$ separation imposed by symmetry. The positions of the heavy atoms in the symmetry plane make possible a clear distinction between the $\sigma$ - and $\pi$-electron networks and the necessary discrimination between the $\sigma$ - and $\pi$-nuclear charges. The stockholder partitioning of the mixed $\Delta V_{\mathrm{ee}}^{\sigma \pi}$ and $\Delta V_{\mathrm{nn}}^{\sigma \pi}$ terms indicates that contributions of the $\sigma$ - and $\pi$-frameworks to the extrinsic aromaticity of benzene $\Delta E$ (ease) $)_{\mathbf{B}}^{\prime}$ are -14.8 and $-23.1 \mathrm{kcal} / \mathrm{mol}$, respectively, yielding the total value of $-37.9 \mathrm{kcal} / \mathrm{mol}$ for the $\mathrm{HF} / \mathrm{cc}-\mathrm{pVTZ}$ model, if 1,3-cyclohexadiene is taken as a nonaromatic reference. Similarly, isomerization reactions 12 and 13 yield $\Delta E(12)$ $=-34.3$ and $\Delta E(13)=-26.6$ respectively, which appears to be a consequence of the favorable $\pi$-electron system.

Obviously, the $\pi$-framework exerts a predominant influence according to quite different reaction schemes, which is significant. The influence of the electron correlation and ZPVEs on aromaticity of benzene is rather small. Taking into account both effects one obtains $\Delta E$ (ease $)_{\mathbf{B}}^{\prime}=-41.4 \mathrm{kcal} / \mathrm{mol}$, according to eq 11. Although $E$ (corr) and ZPVE have to be included in more accurate calculations of aromaticity, they are both irrelevant for a qualitative discussion at the conceptual level and in the semiquantitative estimates.

(3) The main reason behind the aromatic stabilization of $\mathbf{B}$ is a stronger nuclear-electron attraction leading to lower (more negative) $\Delta V_{\mathrm{ne}}^{\sigma}$ and $\Delta V_{\mathrm{ne}}^{\pi}$ numerical values.

(4) Fluorination introduces a destabilization into the aromatic benzene system. It is a consequence of the perturbed $\sigma$-backbone, which leads to an overall destabilization. In contrast, the $\pi$-framework is a stabilizing factor, but to a lesser extent.

(5) Judiciously selected isostructural reactions par excellence 23-33 reveal a remarkable additivity of the substituent effects in polysubstituted fluorobenzenes. It is accurate enough to enable delineation of the aromatic defects and repulsions of $\mathrm{F}$ atoms, in particular those assuming vicinal positions. It turns out that the aromaticity defect increases almost linearly (by factor 2) with the increase in the number of $\mathrm{F}$ atoms placed sequentially at the vicinal positions in systems 3-6. Both effects act in concert, and both arise due to increased electron and nuclear repulsions. The nuclear-electron attractions contribute to the stability of fluorobenzenes, but to a lesser extent. The influence of the total kinetic energy of all $\sigma$ - and $\pi$-electrons is practically negligible.

(6) The present analysis conclusively shows that homodesmotic reactions should be used with extreme care in studying molecular features resulting from some specific intramolecular interactions. The homostructural reactions should be preferred, since the intramolecular interactions are better balanced between educts and products. A caveat emptor should be issued, however, since there are no ideal homodesmotic (or homostructural) reactions. They have to be cautiously selected, so that intramolecular interactions between the studied molecular system and model compounds are matched as close as possible. In particular, 1,3-interactions should be balanced as conclusively shown by Schleyer and co-workers. ${ }^{49,50}$ The best solutions are offered by isostructural reactions, since the fitting of the structures left and right is optimal.

Partitioning of the stabilization energies into the $\sigma$ - and $\pi$-components is a very delicate problem. It cannot be realized in a unique way. Stockholder partitioning seems to be the most realistic one, but in order to prove useful, it should offer a satisfactory description of various substituents exerting different $\sigma$ - and $\pi$-effects. This has to be better investigated.

The question arises whether aromaticity is a notion so vaguely defined that it exists only in the (educated) eyes of a beholder, or it can be specified in a more impartial and unbiased way. 
We feel that (homo)/(iso)structural model reactions accompanied by the energy component analysis possibly offer a convenient means for better characterization of aromaticity. They provide, namely, a deeper insight into the electronic and nuclear intramolecular interactions inherent in cyclic (aromatic) molecules at the global level. However, it is too early to draw final conclusions now.

Acknowledgment. We thank the University Center for Computing SRCE Zagreb for allocation of some computer time on cluster Isabella. Our thanks go also to the John von Neumann Institut für Computing des Forschungszentrums Jülich for computing time within the project "The Correlation Energy of Electrons in Planar Molecules". A part of this work has been accomplished at the University of Heidelberg and one of us (Z.B.M.) would like to thank professor Rolf Gleiter for his interest and the Alexander von Humboldt-Stiftung for financial support. We are indebted to a referee for a number of useful comments.

\section{References and Notes}

(1) Dewar, M. J. S.; Gleicher, G. J. J. Am. Chem. Soc. 1965, 87, 692.

(2) Dewar, M. J. S.; de Llano, C. J. Am. Chem. Soc. 1969, 91, 789

(3) George, P.; Trachtman, M.; Bock, C. W.; Brett, A. M. Theor. Chim. Acta 1975, 38, 121

(4) George, P.; Trachtman, M.; Bock, C. W.; Brett, A. M. J. Chem. Soc., Perkin Trans. 2 1976, 1222

(5) George, P.; Trachtman, M.; Brett, A. M.; Bock, C. W. J. Chem. Soc., Perkin Trans. 2 1977, 1036. 225.

(6) George, P.; Bock, C. W.; Trachtman, M. J. Chem. Educ. 1984, 61 ,

(7) Kistiakowsky, G. B.; Ruhoff, J. R.; Smith, H. A.; Vaughan, W. E. J. Am. Chem. Soc. 1936, 58, 137

(8) Kistiakowsky, G. B.; Ruhoff, J. R.; Smith, H. A.; Vaughan, W. E. J. Am. Chem. Soc. 1936, 58, 146.

(9) Stohmann, F. A. C. J. Prakt. Chem. 1890, 41, 13.

(10) Stohmann, F. A. C. J. Prakt. Chem. 1892, 45, 475.

(11) Katritzky, A. R.; Borczynsky, P.; Musumarra, D.; Pisano, D.; Szafran, M. J. Am. Chem. Soc. 1989, 111, 7.

(12) Schleyer, P. v. R.; Freeman, P. K.; Jiao, H.; Goldfuss, B. Angew. Chem., Int. Ed. Engl. 1995, 34, 337.

(13) Katritzky, A. R.; Karelson, M.; Sild, S.; Krygowski, T. M.; Jug, K. J. Org. Chem. 1998, 63, 5228.

(14) Cyrańsky, M. K.; Krygowski, T. M.; Katritzky, A. R.; Schleyer, P. v. R. J. Org. Chem. 2002, 67, 1333 566.

(16) Schleyer, P. v. R.; Marker, C.; Dransfield, A.; Jiao, H.; van Eikema Hommes, N. J. R. J. Am. Chem. Soc. 1996, 118, 6317.

(17) Schleyer, P. v. R.; Jiao, H. Pure Appl. Chem. 1996, 68, 209.

(18) Jiao, H.; Schleyer, P. v. R.; Mo, Y.; McAllister, M. A.; Tidwell, T. T. J. Am. Chem. Soc. $1997,119,7075$.

(19) Jiao, H.; Schleyer, P. v. R. J. Phys. Org. Chem. 1998, 11, 655.

(20) Schleyer, P. v. R.; Monoharan, M.; Wang, Z.-X.; Kiran, B.; Jiao,

H.; Puchta, R.; van Eikema Hommes, N. J. R. Org. Lett. 2001, 3, 2465.

(21) Heine, T.; Schleyer, P. v. R.; Corminboeuf, C.; Seifert, G.; Reviakine, R.; Weher, J. J. Phys. Chem. A 2000, 107, 6470.

(22) Corminboeuf, C.; Heine, T.; Seifert, G.; Schleyer, P. v. R.; Weber, J. Phys. Chem. Chem. Phys. 2004, 6, 273.

(23) Lazzeretti, P. Ring Currents. In Progress in Nuclear Magnetic Resonance Spectroscopy; Emsley, J. W., Feeney, J., Sutcliffe, L. H., Eds.; Elsevier: New York, 2000; Vol. 36, p 1.

(24) Lazzeretti, P. Phys. Chem. Chem. Phys. 2004, 6, 217.

(25) Krygowski, T. M.; Cyrański, M. K. Chem. Rev. 2001, 101, 1385 and references therein.

(26) Stepień, B. T.; Krygowski, T. M.; Cyrański, M. K. J. Org. Chem. 2002, 67, 5987.
(27) Hückel, E. Z. Phys. 1931, 70, 204

(28) Hückel, E. Z. Phys. 1932, 76, 628

(29) Streitweiser, S., Jr. Molecular Orbital Theory for Organic Chemists; Wiley: New York, 1961

(30) Salem, L. The Molecular Orbital Theory of Conjugated Systems; Benjamin, W. A.: New York, 1966.

(31) Longuet-Higgins, H. C.; Salem, L. Proc. R. Soc. London 1959 , A251, 172 .

(32) Kutzelnigg, W. Einführung in die Theoretische Chemie, 3rd ed.; Verlag Chemie: Weinheim, 2002; Band 2 and references therein.

(33) Heilbronner, E. J. Chem. Educ. 1989, 66, 471.

(34) Berry, R. S. J. Chem. Phys. 1961, 35, 2253

(35) Gobbi, A.; Yamaguchi, Y.; Frenking, G.; Schaefer, H. F., III. Chem Phys. Lett. 1995, 244, 27.

(36) Yamaguchi, Y.; Remington, R. B.; Gaw, J. F.; Schaefer, H. F., III; Frenking, G. J. Chem. Phys. 1993, 98, 8749

(37) Shaik, S.; Shurki, A.; Danovich, D.; Hiberty, P. C. Chem. Rev. 2001, 101, 1501 and references therein.

(38) Jug, K.; Köster, A. M. J. Am. Chem. Soc. 1990, 112, 6772

(39) Jug, K.; Hiberty, P. C.; Shaik, S. Chem. Rev. 2001, 101, 1477.

(40) Kovačević, B.; Barić, D.; Maksić, Z. B.; Müller, T. ChemPhysChem $20045,1352$.

(41) Dunning, T. H., Jr. J. Chem. Phys. 1989, 90, 1007.

(42) Frisch, M. J.; Trucks, G. W.; Schlegel, H. B.; Scuseria, G. E.; Robb M. A.; Cheeseman, J. R.; Montgomery, J. A., Jr.; Vreven, T.; Kudin, K. N.; Burant, J. C.; Millam, J. M.; Iyengar, S. S.; Tomasi, J.; Barone, V.; Mennucci, B.; Cossi, M.; Scalmani, G.; Rega, N.; Petersson, G. A.; Nakatsuji, H.; Hada, M.; Ehara, M.; Toyota, K.; Fukuda, R.; Hasegawa, J.; Ishida, M.; Nakajima, T.; Honda, Y.; Kitao, O.; Nakai, H.; Klene, M.; Li, X.; Knox, J. E.; Hratchian, H. P.; Cross, J. B.; Bakken, V.; Adamo, C.; Jaramillo, J.; Gomperts, R.; Stratmann, R. E.; Yazyev, O.; Austin, A. J.; Cammi, R.; Pomelli, C.; Ochterski, J. W.; Ayala, P. Y.; Morokuma, K.; Voth, G. A.; Salvador, P.; Dannenberg, J. J.; Zakrzewski, V. G.; Dapprich, S.; Daniels, A. D.; Strain, M. C.; Farkas, O.; Malick, D. K.; Rabuck, A. D.; Raghavachari, K.; Foresman, J. B.; Ortiz, J. V.; Cui, Q.; Baboul, A. G.; Clifford, S.; Cioslowski, J.; Stefanov, B. B.; Liu, G.; Liashenko, A. Piskorz, P.; Komaromi, I.; Martin, R. L.; Fox, D. J.; Keith, T.; Al-Laham, M. A.; Peng, C. Y.; Nanayakkara, A.; Challacombe, M.; Gill, P. M. W. Johnson, B.; Chen, W.; Wong, M. W.; Gonzalez, C.; and Pople, J. A. Gaussian 03, revision B.03; Gaussian, Inc.: Pittsburgh, PA, 2003.

(43) Maksić, Z. B.; Barić, D.; Petanjek, I. J. Phys. Chem. A 2000, 104, 10873

(44) Parr, R. G. Quantum Theory of Molecular Electron Structure; Benjamin, W. A.: New York, 1963.

(45) Fock, V. Z. Phys. 1930, 63, 855.

(46) Slater, J. C. J. Chem. Phys. 1933, 1, 687.

(47) Löwdin, P. O. J. Mol. Spectrosc. 1959, 3, 46

(48) Wodrich, M. D.; Wannere, C. S.; Mo, Y.; Jarowski, P. D.; Houk, K. N.; Schleyer, P. v. R. Submitted for publication. We thank professor Schleyer for making this material available prior to publication.

(49) Schleyer, P. v. R.; Puhlhofer, F. Org. Lett. 2002, 4, 2873.

(50) Wannere, C. S.; Moran, D.; Allinger, N. L.; Hess, B. A., Jr.; Schaad, L. J.; Schleyer, P. v. R. Org. Lett. 2003, 5, 2983.

(51) Chesnut, D. B.; Davis, K. M. J. Comput. Chem. 1996, 18, 584

(52) Barić, D.; Maksić, Z. B.; Yáñez, M. Mol. Phys 2003, 101, 1377.

(53) Barić, D.; Maksić, Z. B. J. Phys. Chem. A 2002, 106, 1612.

(54) Barić, D.; Maksić, Z. B. J. Phys. Chem. A 2003, 107, 11577.

(55) Maksić, Z. B.; Barić, D.; Petanjek, I. J. Phys. Chem. A 2000, 104, 10873.

(57) Barić, D.; Maksić, Z. B. J. Phys. Org. Chem. 2003, 16, 753.

(58) Smith, D. M.; Barić, D.; Maksić, Z. B. J. Chem. Phys. 2001, 115, 3474.

(59) Schulman, J. M.; Disch, R. L. Chem. Phys. Lett. 1985, 113, 291

(60) Ibrahim, M. R.; Fataftah, Z. A. Chem. Phys. Lett. 1986 125, 149.

(61) Barić, D.; Maksić, Z. B.; Vianello, R. J. Mol. Struct. (THEOCHEM) 2003, 672, 201

(62) Sinha, P.; Boesch, S. E.; Gu, C.; Wheeler, R. A.; Wilson, A. K. J. Phys. Chem. A 2004, 108, 9213 . 